\title{
Las imperfecciones del mercado de créditos, la restricción crediticia y los créditos alternativos
}

\section{The Credit Market Imperfection, Credit Constraints and Alternative Credits in the Capital Market}

Gustavo Adolfo Díaz Valencia*

Artículo de reflexión e investigación

Cómo citar este artículo: Díaz Valencia, G. A. (2011). Las imperfecciones del mercado de créditos, la restricción crediticia y los créditos alternativos. Revista CIFE, 17, (12), 103 - 133.

\section{Resumen}

El siguiente artículo tiene como objetivo presentar de manera general algunos fundamentos teóricos y empíricos relacionados con las imperfecciones del mercado de créditos que conllevan a la restricción del crédito, la aparición del crédito informal y la propuesta de canales alternativos de financiación como los microcréditos, con el fin de analizar los alcances y las limitaciones de estas actividades financieras, las cuales en muchas ocasiones son excluyentes para los pequeños productores informa- les, los productores agrícolas, los trabajadores por cuenta propia y numerosos grupos sociales, quienes enfrentan grandes dificultades para acceder a este tipo de recursos, por no disponer de los suficientes ingresos y garantías reales que respalden estas obligaciones financieras. Por ello, es importante plantear una reflexión en el sentido de analizar si el crédito como vehículo de financiación facilita el desarrollo de las actividades económicas o por el contrario, se ha convertido en una actividad cada vez más excluyente especialmente para aquellos sectores más vulnerables de la población, que limita aún más el

\footnotetext{
* Economista de la Universidad Nacional de Colombia. Doctor en Ciencias Económicas de la Universidad Nacional de Colombia. Docente de la Maestría en Ciencias Económicas de la Universidad Santo Tomas. Miembro del Grupo de investigación GRIES. Correo electrónico: <gustavodiaz@usantotomas.edu.co>.
} 
mejoramiento de sus condiciones de vida. Asimismo, se efectuará una breve caracterización del microcrédito en Colombia, su evolución, y los principales alcances que han tenido los usuarios de estos créditos.

Palabras clave: microcrédito, crédito informal, crédito racionado, riesgo de crédito.

Clasificación JEL: G10, G11.

\section{Abstract}

The following article presents in a general way some theoretical and empirical studies related to credit market imperfections that lead to credit tightening, the emergence of informal credit capital, and that of alternative financing channels such as microcredit, in order to analyze the scope and limitations of these financial activities, which

\section{Introducción}

En economías con mercados de capitales poco desarrollados como Colombia, el sistema bancario es el principal proveedor de créditos a los hogares y a las empresas, convirtiéndose así en un agente central para la actividad productiva. Es así como un racionamiento de crédito puede causar un deterioro en la actividad económica. En economías como la colombiana, problemas de racionamiento de crédito pueden causar un deterioro en la actividad económica y la exclusión de muchos agentes económicos al acceso de recursos financieros. Por tal razón, cobra relevancia identificar los determinantes de la demanda y oferta de crédito para establecer en qué eventos pueden haber restricciones crediticias. En este trabajo se lleva a cabo un análisis de desequilibrio para el mercado de crédito a nivel teórico que genera restricciones crediti- in many cases are exclusive to small informal entrepreneurs, farmers, self-employed and many social groups who face great difficulties in accessing these resources, due to the fact they not do have sufficient income and collateral support for these credits. It is therefore important to conduct an analysis to observe if credit as a vehicle for funding facilitates the development of economic activities or otherwise, become an increasingly exclusive activity for the most vulnerable sectors of the population, further limiting the improvement of their living conditions. The article will also make a brief characterization of microcredit in Colombia, its evolution, and major achievements of those who have used these credits.

Key words: Micro-credit, Informal Credit, Credit Rationing, Credit Risk.

\section{JEL Classificatión: G10, G11.}

cias y el surgimiento de canales alternativos de financiación, como los créditos informales y los microcréditos, en ocasiones otorgados con desventajas para los usuarios de estos recursos. También se analizará el comportamiento de la restricción de crédito para Colombia y los microcréditos a nivel macroeconómico.

En muchas economías pobres el crédito es esencial para facilitar la financiación de las actividades de capital de trabajo y la inversión fija en los procesos productivos, principalmente para la gran mayoría de pequeños establecimientos de la llamada economía informal. Una fracción importante de las operaciones crediticias en los países subdesarrollados toma lugar en el sector informal (trabajadores independientes, microempresarios, productores agrícolas), donde los gobiernos se han esforzado por crear actividades financieras que permitan el acceso a estos recursos en condiciones especiales. Tal es el caso de los créditos de fomen- 
to canalizados a través de la banca de segundo piso con operaciones de redescuento, regulando políticas crediticias de los bancos comerciales, cooperativas y ONG, e implementando los microcréditos. En otras ocasiones se han establecido canales de créditos alternativos no institucionales bajo la modalidad de créditos informales, los cuales a pesar de no tener muchos requerimientos, resultan demasiado costosos y riesgosos para los usuarios.

No obstante lo anterior, estas opciones resultan insuficientes para atender las necesidades de financiación de un gran número de agentes económicos que pertenecen al sector informal, entre ellos los trabajadores independientes, las pequeñas y medianas empresas y en general de los sectores más vulnerables de la población, quienes no tienen la mínima posibilidad de acceder a los créditos, pues no poseen ningún patrimonio o carecen parcial o totalmente de cualquier tipo de recursos que respalden estas operaciones.

Por tanto, los diferentes estudios propuestos a través de las líneas generales de investigación que analizan el crédito y su relación con el riesgo se han centrado principalmente en problemas como: la selección adversa (información oculta), el riesgo moral (acción oculta) y la ejecución de contratos dada la imposibilidad de cumplimiento en las condiciones de pago, bajo la amenaza de no permitir el acceso a futuros créditos, o el reporte permanente en las centrales de riesgo.

Estos aspectos reflejan parte de la realidad de los países en desarrollo, pues inducen a incrementar la desigualdad, principalmente en los sectores con poca o ninguna riqueza, los cuales quedan totalmente excluidos de cualquier posibilidad de financiación al enfrentarse a elevados costos que implican la intermediación de los recursos, así como la cantidad de requerimientos que exigen las entidades financieras para aprobar nuevas solicitudes o al abuso de los prestamistas informales quienes se aprovechan de las necesidades de demanda de recursos de los usuarios de crédito, imponiendo elevadas tasas de interés que superan a las del mercado y en el peor de los casos terminan apropiándose del patrimonio de los prestatarios.

De este modo, el objetivo de este artículo es desarrollar de manera general un análisis de las imperfecciones del mercado de créditos, y su relación con el racionamiento y la aparición de canales alternativos de financiación, tanto desde el punto de vista teórico como desde el punto de vista macroeconómico para el caso colombiano, con el fin de identificar cuáles son las principales limitantes que afrontan aquellos productores, especialmente los informales o los hogares de menores ingresos, para el desarrollo de sus actividades económicas.

En este artículo se desarrollaron los siguientes puntos: un análisis general desde el punto de vista teórico relacionado con el mercado de capitales y de los créditos en un escenario de equilibrio y de competencia imperfecta; una caracterización del crédito racionado y el crédito informal; y por último, una breve presentación del comportamiento crediticio en Colombia y su relación con la restricción, así como el desarrollo de créditos alternativos como los microcréditos en Colombia, especialmente como una actividad de financiación para aquellos productores de la economía informal.

\subsection{Metodología}

Este artículo se orienta a revisar e indagar el marco teórico relacionado con la restricción de créditos y las imperfecciones del mercado de créditos, contrastando los modelos de equilibrio general walrasiano con los desequilibrios del mercado de capitales, los cuales han dificultado el acceso de recursos a diferentes sectores sociales. Posteriormente, se analizarán a partir de algunas evidencias empíricas basadas en estudios recientes, la evolución crediticia en Colombia durante la última década y la comparación de 
créditos formales e informales analizados a partir de una encuesta elaborada por Econométrica para el año 2007, que muestra las incidencias que ha presentado el otorgamiento de recursos tanto a microempresas como a hogares. Lo anterior sirve de insumo para desarrollar posteriormente una investigación sobre el tema de las microfinanzas como factor de democratización del crédito en Colombia.

\section{Un modelo simple del mercado de capitales en equilibrio}

Desde el punto de vista de los mercados, se considera que en una situación de equilibrio y competencia perfecta existe una coordinación entre prestamistas y prestatarios, de tal manera que la distribución de recursos generados por el ahorro en el mercado de capitales garantiza el desarrollo de la inversión.

El equilibrio del mercado de capitales se puede explicar a partir de un modelo simple de equilibrio walrasiano donde los agentes optimizan su función objetivo y los mercados se vacían. En el caso concreto del equilibrio walrasiano, los agentes además de elegir las asignaciones óptimas de consumo, eligen también el nivel de préstamos óptimos. Por otro lado, además del vaciado en el mercado de bienes, también se necesita que el mercado de capitales se vacíe. En un modelo sencillo el vaciado del mercado de capitales se produce cuando la suma agregada de los préstamos es igual a cero. Esto es así porque cualquier préstamo concedido $\left(L_{i}>0\right)$ tiene su contrapartida en un préstamo recibido $\left(L_{l} l<0\right)$. A nivel agregado, ambos se cancelan y la oferta neta de préstamos es igual a cero. Por tanto, el equilibrio financiero en la economía $\xi=\left\{\left(u_{i}(.) y_{i}\right) i=1 \ldots l\right\}$ se define de la siguiente manera:
Las variables relevantes de éste modelo son:

Las preferencias de consumo están definidas por la función de utilidad $U_{i}\left(c_{i}\right), i=1 \ldots . . l$

Los recursos de los agentes $y_{i}=\left(y_{i 0} \cdot y_{i l}\right)$

La dotación de recursos como la riqueza o renta actual $y_{i 0}$ y la riqueza o renta futura $y_{i 1}$.

El consumo de cada agente $. c_{i}=\left(c_{i 0} \cdot c_{i l}\right)$.

(r): es la tasa de interés.

Dados los precios de los bienes de consumo y la tasa de interés $\left(p_{0} p_{1} \cdot r\right)$ de los préstamos para cada agente $i,\left(c_{\mathrm{i}} l_{\mathrm{i}}\right)$ la solución al problema de optimización se define como (Marín y Rubio, 2001, pp. 680-685):

$\operatorname{Max} U_{\mathrm{i}}\left(c_{\mathrm{i} 0} \cdot c_{\mathrm{i} 1}\right)(2)$

$c_{\mathrm{i} 0} \cdot c_{\mathrm{i} 1} \cdot l_{\mathrm{i}}$

s. $a p_{0} c_{\mathrm{i} 0}=p_{0} c_{\mathrm{i} 0}-L_{\mathrm{i}}$

$p_{1} c_{\mathrm{i} 1}=p_{1} c_{\mathrm{i} 1}-L_{\mathrm{i}}(1+\mathrm{r})$

$c_{\mathrm{i} 0} \geq 0, \quad c_{\mathrm{i} 1} \geq 0$

El vaciado de los mercados $\left(p_{0} p_{1} \cdot r\right)$ es tal que la demanda es igual a la oferta en todos los mercados:

$\sum_{i=1}^{1} c_{i 0}=\sum_{i=1}^{1} y_{i o}$ mo del momento $\mathrm{t}=0$ )

$\left\{\left(c_{i} L_{I}\right) i=1 \ldots . I, p . r\right\}(1)$ 
$\sum_{\mathrm{i}=1}^{1} c_{\mathrm{i} 1}=\sum_{\mathrm{i}=1}^{1} y_{\mathrm{i} 1}$ Vaciado del mercado de bienes de consumo en el período $t=1$ )

$\sum_{i=!}^{1} L_{i}=0$

(Vaciado mercado de capitales)

El proceso anterior describe el equilibrio walrasiano, el cual sirve de base para analizar el equilibrio financiero, partiendo de la base de que las condiciones sobre las funciones de utilidad y presupuestos son las mismas del equilibrio walrasinano. En el mercado financiero los agentes se enfrentan a una única restricción presupuestaria intertemporal, donde la variable más importante que se determina en este mercado es la tasa de interés de equilibrio de la economía.

El modelo de equilibrio financiero se presenta como:

$$
\begin{aligned}
& \text { Max } U_{\mathrm{i}}\left(c_{\mathrm{i} 0} \cdot c_{\mathrm{i} 1}\right)(3) \\
& \text { Sujeto a: } c_{\mathrm{io}}+\frac{1}{1+\mathrm{r}} c_{\mathrm{i} 1}=y_{\mathrm{io}}+\frac{1}{1+\mathrm{r}} y_{\mathrm{i} 1} \\
& c_{\mathrm{i} 0} \geq 0, \quad c_{\mathrm{i} 1} \geq 0 \\
& \sum_{\mathrm{i}=1}^{1} c_{\mathrm{i} 0}=\sum_{\mathrm{i}=1}^{1} y_{\mathrm{i} 1} \\
& \sum_{\mathrm{i}=1}^{1} c_{\mathrm{i} 1}=\sum_{\mathrm{i}=1}^{1} y_{\mathrm{i} 1} \\
& \sum_{\mathrm{i}=1}^{1} L_{\mathrm{i}}=0
\end{aligned}
$$

Dado lo anterior, se deduce que si el equilibrio walrasiano existe, el financiero también existe, y dado que las dotaciones iniciales son asignaciones no eficientes, el único activo financiero para completar los mercados son los préstamos y dar lugar a equilibrio con asignaciones de Pareto eficientes. Si dicho activo no existiese, se presentaría una situación de mercados financieros incompletos, siendo las asignaciones de equilibrio no eficientes en el sentido de Pareto.

\section{El crédito en un mercado de capitales imperfecto}

A diferencia de un mercado de competencia perfecta donde no hay diferenciación entre los empresarios -es decir, todos los agentes participan en las mismas condiciones-, el mercado facilita la asignación de los recursos a través del ahorro, para llevar a cabo las actividades de inversión.

En un mercado de capitales imperfecto y con incertidumbre, las empresas presentan diferencias en cuanto a la disponibilidad de recursos, tamaño de la planta y posicionamiento en los mercados. Algunas van a tener más dificultades de pago que otras, pues no todas las empresas disponen de recursos que garanticen el retorno de las obligaciones con las entidades financieras.

Si una empresa grande quiere evitar recurrir al sistema financiero busca formas alternativas de financiación, bien sea emitiendo bonos o utilizando las ganancias retenidas. Sin embargo, si sus recursos son inferiores a sus necesidades de capital, entonces recurren al crédito.

Cuando los mercados presentan fallas, es necesario plantear las probabilidades de cumplimiento o incumplimiento en el pago de las obligaciones y el riesgo de crédito que pueden enfrentar los empresarios con el sistema financiero. 
Por tanto, al momento de financiar un proyecto de inversión los empresarios buscan que éste genere no sólo beneficios a la empresa sino que también garantice el pago de las obligaciones. Si las empresas son pequeñas o medianas las posibilidades de financiación son aún más excluyentes, especialmente aquellos pequeños productores para los cuales el retorno de sus inversiones no garantiza suficientemente la amortización de la obligación y asimismo no cuentan con las suficientes garantías que respaldan estas operaciones. En muchas ocasiones estos agentes son catalogados por las entidades financieras como de alto riesgo, dando lugar así al racionamiento de los créditos.

En conclusión, cuando los mercados son imperfectos y presentan fallas, el flujo de recursos es otorgado bajo ciertas condiciones. Si la riqueza de los empresarios es menor a las necesidades de inversión en capital fijo, se recurre a la financiación. Si el empresario presenta un proyecto de inversión, es necesario que su flujo de fondos garantice el pago de la financiación a través del retorno esperado del proyecto; sin embargo, cuando el agente se expone a una serie de riesgos bien sea inherentes al mercado, al aumento de las tasas de interés o a dificultades en el funcionamiento mismo de la empresa, ocurren posibilidades de impago u otras externalidades que limitan el acceso a recursos en el futuro.

\subsection{El crédito racionado en el mercado de capitales}

Autores como Keeton (1979), Stiglitz y Weiss (1981) han desarrollado el concepto del crédito racionado. Dado que los mercados son imperfectos y más aún el de capitales, se han considerado algunos motivos que limitan el acceso a los recursos financieros especialmente en situaciones en las cuales la tasa de interés sufre variaciones inesperadas, ocasionadas por riesgos de mercado y riesgos sistémicos asociados al ciclo de la economía (Guillen Romo, 1997):

El riesgo sistémico está explicado por un desajuste del mercado que provoca fluctuaciones importantes del precio de los activos sin relación con su valor fundamental. También se presenta riesgo sistémico cuando el crédito está asociado al comportamiento del ciclo económico el cual tiene su origen en factores reales impulsados por las anticipaciones de producción de los empresarios.

Entre los motivos que han permitido el desarrollo del concepto del crédito racionado se destacan los siguientes:

- El riesgo moral cuando el usuario del crédito anuncia al acreedor (agente no informado) que los malos resultados de los proyectos de inversión son consecuencia de eventos independientes a su voluntad. De otra parte, el agente no informado puede observar la acción pero no puede verificar si es apropiada y no puede apreciar las circunstancias en las cuales se desarrolló la acción (Cahuc, 1999).

- Cuando hay selección adversa, se designa un efecto perverso en el funcionamiento de los mercados debido a ciertos problemas de información por parte de los acreedores. Entonces los prestamistas prefieren racionar los préstamos especialmente cuando se incrementa la tasa de interés, y aumenta la posibilidad de impago. En este caso la fluctuación de la tasa de interés muestra una señal de la aversión al riesgo de los agentes.

- Otro de los argumentos que conllevan a un racionamiento de los créditos está relacionado con la asimetría de información entre los bancos y los prestamistas. En muchas ocasiones, uno u otro ocultan información fundamental, con el objetivo de otorgar 
o acceder a recursos. Esta situación conlleva a un problema de identificación de aquellos agentes empresariales que necesitan créditos. En muchas ocasiones sólo se concede a aquellos que ofrezcan garantías reales para cubrir sus compromisos.

La teoría neokeynesiana considera que la asimetría de información es la base para racionar los créditos, donde la probabilidad de distribución de los retornos de cada proyecto es conocida por el usuario del crédito pero no por el banco, el cual sólo tiene información del valor esperado de la tasa interna de retorno del proyecto, pero no tiene certeza de sus riesgos. Por tanto, el banco puede tener conocimiento de que un incremento de la tasa de interés puede afectar adversamente el proyecto y aumentar el riesgo de no pago del crédito. Los riesgos pueden cambiar por dos efectos: por la selección adversa y el riesgo moral.

De otro lado, el banco también puede suponer que el aumento en la tasa de interés tiene cierto incentivo en la elección de los proyectos de inversión. Como las tasas de interés aumentan, cualquier prestatario tendrá la tendencia a seleccionar aquellos proyectos que impliquen más riesgo, pues tienen una rentabilidad más alta cuando tienen éxito (y una rentabilidad más baja cuando pierdan). La razón es que buscan proyectos con elevadas tasas de retorno para pagar las elevadas tasas de interés.

Por otra parte, Hodgman (1960) considera que el atractivo de solicitar un crédito para efectuar una inversión depende de varios factores: la tasa de interés, el riesgo y los posibles beneficios que genere el proyecto a largo plazo. Tanto el rendimiento como los diversos aspectos del riesgo de una inversión están relacionados entre sí y pueden variar entre los prestatarios sólo dentro de límites específicos. El aporte de este autor es considerar la calificación crediticia del prestatario, donde el riesgo de pér- dida es una función creciente del tamaño del préstamo, mientras que el valor esperado de las posibles ganancias y pérdidas (como una medida de rendimiento bajo condiciones de riesgo) es una función creciente de la cantidad que el prestatario promete a devolver (incluido el interés). Sin embargo, la influencia de la calificación de los prestatarios de créditos establece un tope máximo para el valor esperado de la rentabilidad, mientras que no hay límite para analizar la pérdida esperada.

Otros autores neokeynesianos, trabajan en un contexto macroeconómico utilizando los mismos supuestos de información asimétrica para llegar a resultados diferentes. Estas teorías suponen que la información asimétrica genera problemas a todos los prestamistas. Pero en lugar de centrarse en los problemas que puedan ocasionar ciertos prestamistas, estas teorías destacan la capacidad relativa de unos bancos para superar la información incompleta. Así, ciertas entidades se especializan en obtener información preliminar sobre los clientes, en evaluar a través de una calificación previa los proyectos inversión, en hacer un seguimiento de los créditos después de la recepción de un préstamo a través del control a las inversiones, y en elaborar estudios de análisis sectorial y macroeconómico de los mercados ${ }^{1}$.

$\mathrm{Al}$ analizar en detalle la información preliminar de los solicitantes de crédito, un sistema de reputación ayuda a disciplinar a estos usuarios. Si una persona o una empresa incumplen en el pago de sus obligaciones, esto puede destruir su reputación y se califica como de alto riesgo, por ello las centrales de riesgo difunden información sobre el impago de personas en una comunidad. Cuando los bancos tienen información limitada sobre la conducta de los prestatarios

1 Aquí los bancos pueden trabajar con todos los intermediarios (incluyendo fondos de pensiones y corredores de bolsa) quienes tienen capacidad de obtener información especializada de los clientes. 
buscan información de los nuevos usuarios con mucha cautela y dedican recursos y tiempo para verificar la información. Por supuesto que estos procesos no suceden en un sistema de créditos informal, aunque allí el prestamista tiene cierto conocimiento personal del historial de sus clientes.

La importancia de este enfoque radica en que utiliza el análisis macroeconómico para conocer no sólo la información de los usuarios del crédito sino también para conocer el efecto de las implicaciones macroeconómicas que perturban el normal funcionamiento de la actividad bancaria y puedan reducir la oferta de crédito a los prestatarios. Esta idea ha dado lugar a explicar porqué la disminución de la actividad económica obedece a restricciones en los préstamos bancarios en diferentes contextos.

Sobre la base anterior se argumenta que la existencia de un canal de crédito no depende del crédito racionado. En este sentido, Bernanke (1993) explica:

El racionamiento del crédito (...) es consistente con la existencia de los canales de crédito (...) Sin embargo, el racionamiento de crédito no es todo lo necesario para que el canal de crédito exista. Todo lo que necesita un canal de crédito es que el crédito bancario y otras modalidades de crédito sean sustitutos imperfectos para los prestatarios. Por lo tanto, el hecho de existan muchos deudores potenciales del crédito alternativo no elimina el canal de crédito convencional (Bernanke, 1993, p. 55).

De hecho, la discusión de la crisis crediticia de principios de los años noventa podría estar explicada por el racionamiento del crédito. Según Bernake y Lown (1991), define una contracción del crédito bancario como una reducción en la oferta de créditos dada la fuerte restricción a la aprobación de nuevas solicitudes, que gráficamente se refleja en un desplazamiento hacia la izquierda en la curva de oferta de préstamos de los bancos, manteniendo constante tanto la tasa de interés real de seguridad como la calidad de los prestatarios potenciales (figura 1). r tasa de interés

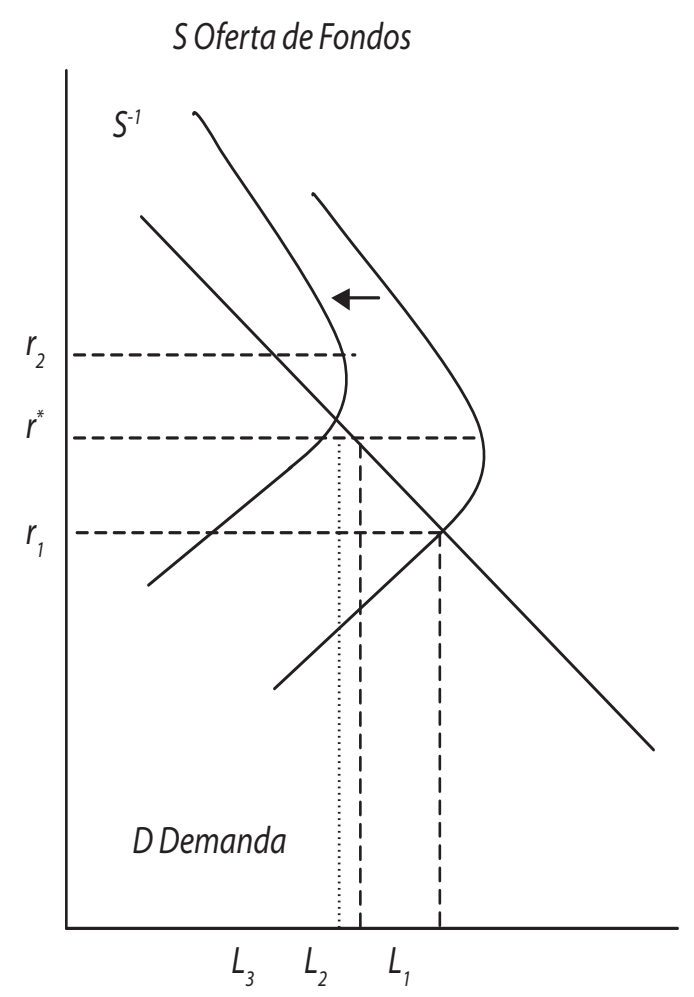

Figura 1. Crédito racionado con información asimétrica Fuente: Bernanke (1993, p. 55)

Stiglitz y Weiss $(1981,1983)$ desarrollaron el concepto de crédito racionado cuando hay información asimétrica y no hay regulación en los bancos competitivos. Consideran el potencial del crédito racionado como una simple combinación de solicitantes de préstamos, donde cada uno presenta un proyecto con la misma tasa de retorno. 
Estos autores analizan el comportamiento de la demanda total de fondos prestables del todo el sector bancario, la cual se deriva de examinar los efectos de los cambios en la tasa de interés a lo largo de diferentes combinaciones de créditos. Esto muestra que si cada selección adversa ocurre en cada combinación de riesgo, el banco decide si aprueba o no el crédito.

La estructura del modelo W-S identifica una combinación de solicitantes de crédito, quienes tienen proyectos con iguales requerimientos de financiación y el mismo retorno esperado $\mu$.

Los bancos también son conscientes de que aunque los proyectos tengan la misma tasa media de retorno, ellos difieren en sus riesgos. La aplicación de préstamos en una clase de riesgos tiene una función de distribución acumulada de un retorno $x$ de $F(x-\mu$; s). Se asume que los riesgos de los préstamos pueden ser ordenados de acuerdo a un criterio aleatorio, donde una mayor clase de riesgos s representa un mayor riesgo del préstamo. La información asimétrica es introducida porque se asume que cada solicitante del crédito conoce el tipo de riesgo de su proyecto (s), pero los prestamistas sólo conocen de los solicitantes de los créditos la función de distribución de los retornos de su inversión en los flujos de caja.

El problema es que la presencia de información asimétrica hace difícil establecer uno a uno la relación entre la clase de riesgo y la tasa de interés, además la incertidumbre hace dificil identificar la clase de riesgo. Por tanto, los bancos y el sistema financiero necesitan alguna forma de clasificar las nuevas solicitudes de crédito, tomando como referencia el scoring de los créditos de períodos pasados y de los nuevos proyectos y simplemente no otorgan recursos cuando las solicitudes y los proyectos presentan inconsistencias y no se entienden.
A partir de lo anterior, se define una función demanda de fondos prestables que depende de la tasa de interés de equilibrio de los préstamos y la media de la tasa de retorno de los proyectos. Formalmente, la tasa de equilibrio de los préstamos está definida como $r=R(i ; \mu)$ (Rilley, 1987, p. 225) y está dada implícitamente por la condición de beneficio cero $p(i ; \mu)=i$.

La demanda de fondos prestables se define como:

$\mathrm{L}=\mathrm{D}(\mathrm{i}, \boldsymbol{\mu})=\mathrm{L}(\mathrm{R}(\mathrm{i} ; \boldsymbol{\mu}) ; \boldsymbol{\mu})(5)$

Por tanto, la demanda de fondos prestables disminuye continuamente con un incremento en la tasa de interés hasta $i=p^{*}(\boldsymbol{\mu})$. En este punto el retorno esperado por unidad de capital invertido es un máximo. Además si la tasa de interés aumenta $\mathrm{p}^{*}(\boldsymbol{\mu})$, la demanda de fondos prestables tiende a cero. Así la curva de demanda $D(i ; \mu)$ es discontinua en $\mathrm{i}=\mathrm{p}^{*}(\boldsymbol{\mu})$ (figura 2 ).

El paso final de este argumento es agregar el riesgo observable de los proyectos en el análisis del crédito.

A partir de la tasa máxima de beneficio esperado $\mathrm{p}^{*}(\mu)$, la cual incrementa con base en la tasa media de retorno $\mu$, el inversionista espera aumentar su beneficio de acuerdo al retorno de su proyecto $p(r: \mu)$, lo cual implica que los inversionistas estarían tentados a ejecutar proyectos que impliquen un mayor riesgo y asumir el costo de la deuda.

La discontinuidad ocurre cuando aumenta la tasa de préstamo del banco, dada una combinación de riesgos, con una tasa media de retorno $\mu_{k}$. Adicionando las clases de riesgos, la demanda agregada de fondos prestables está definida como:

$\mathrm{D}(\mathrm{i})=\sum \mathrm{D}\left(\mathrm{i}: \mu_{k}\right)(6)$ 
Costo de los préstamos (tasa de interés)

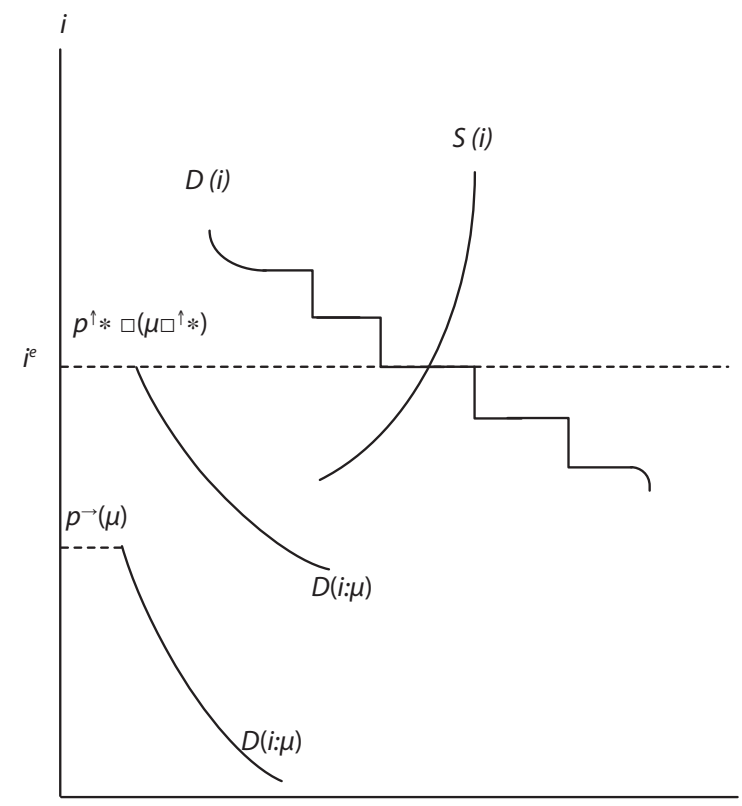

Fondos prestables $L$

Figura 2. Equilibrio en el mercado de fondos prestables

Fuente: Rilley (1987).

En la figura 2 se observa que la curva de oferta de fondos prestables (sli) presenta un pendiente positiva mientras la demanda de fondos prestables tiene pendiente negativa y se presenta en forma discontinua, por la combinación entre tasa de interés y el retorno de los proyectos. Sobre esta base se pueden presentar las siguientes situaciones: aquellos grupos de solicitantes de créditos para quienes el retorno de sus proyectos $\mathrm{p} *(\mu)$ está por debajo de los costos de equilibrio de los fondos prestables ie se consideran improductivos y quedan excluidos; por el contrario, cuando el grupo de solicitantes tiene un retorno más alto que la tasa de interés de equilibrio $\mathrm{p}^{*}(\boldsymbol{\mu})>\mathrm{ie}$, su nivel de endeudamiento aumenta y se enfrentan a mayores riesgos, pero dada la rentabilidad de sus proyectos ésta permite cubrir el costo de la deuda, lo cual facilita la aprobación de sus solicitudes. Finalmente, en equilibrio cuando la oferta de fondos prestables es igual a la demanda, la tasa de equilibrio de deuda es $\mathrm{re}=\mathrm{R}(\mathrm{ie}, \boldsymbol{\mu})$.

Williamson (1987) construye un modelo con información asimétrica y costo de monitoreo, en donde el equilibrio de crédito racionado se presenta en ausencia de selección adversa y riesgo moral, y los contratos se derivan de acuerdos óptimos entre prestamistas y prestatarios. Los contratos son evaluados en términos de la tasa de retornos ofrecida por ellos. La tasa esperada de los retornos de los prestamistas juega un rol de precios en el mercado de los créditos.

Una ventaja de la propuesta de Williamson es que los contratos de deuda pueden derivarse de acuerdos óptimos entre prestamistas y prestatarios, de tal manera que los contratos sirvan para reducir los costos de monitoreo. Este modelo es similar al de los costos de verificación por etapas desarrollado por Townsend (1979), y Gale y Hellwing (1984), aunque ninguno de estos autores estudió las implicaciones de sus modelos con relación a los créditos racionados.

Dado que el contrato óptimo es un contrato de deuda, la probabilidad de que ocurra un monitoreo hace que el costo de monitoreo de los préstamos aumente con la tasa de interés del préstamo.

\subsection{Algunos factores que explican la restricción del crédito}

Según Bernanke y Lown (1991), el apretón crediticio tiene lugar cuando, pese a que las tasas de interés reales se mantienen estables (constantes) y el perfil de riesgo de los potenciales deudores (fundamentalmente la capacidad de 
pago) no se altera, la oferta de créditos por parte del sector financiero se contrae.

Una definición alternativa (Browne y Rosengren, 1992) establece que la restricción crediticia es el racionamiento del crédito por la vía de cantidades y no de precios; en otras palabras, que el deterioro en la dinámica del crédito obedece a factores de oferta, siempre que la reducción en la disponibilidad de recursos prestables no sea motivada por variaciones en las tasas de interés.

En buena parte de la literatura en la que se analiza el tema de restricción del crédito a partir de una contracción en la oferta de recursos, se establece que el comportamiento de la economía y las expectativas que se tienen sobre el crecimiento de la misma son factores determinantes en la toma de decisiones de crédito por parte de las entidades financieras. En la medida en que exista una percepción desfavorable de la situación económica y con ella, la perspectiva de un deterioro en la capacidad de pago de los potenciales deudores, el sector financiero estaría dispuesto a asumir un menor riesgo en el otorgamiento de nuevos créditos.

En algunos estudios se establece que la restricción del crédito ofrecido por el sector financiero es una señal de la recomposición de los balances de los establecimientos financieros, motivada por una reducción en los depósitos. En cuanto a las causas que motivan la ocurrencia de un apretón crediticio, Clair y Tucker (1993) identifican los siguientes factores como determinantes en este proceso:

- "Reducción en el capital de las entidades financieras. Cuando la economía atraviesa por un período de desaceleración, se genera un deterioro en la capacidad de pago por parte de los deudores del sector financiero; por este concepto, las entidades se ven obligadas a realizar mayores esfuerzos de provisiones de cartera, lo cual se traduce en una reducción en la capacidad patrimonial del sector para apalancar nuevas colocaciones.

- Reducción en los depósitos del sistema financiero. La caída en los depósitos o recursos prestables, motivada en buena medida por la existencia de alternativas con mayor rentabilidad por fuera del sistema financiero. De la misma manera, se generan presiones para apalancar los créditos vigentes sin que ocurra un deterioro de la capacidad de pago de los mismos.

- Reacción de la supervisión bancaria. La introducción de una regulación y supervisión más estrictas que lleva a los intermediarios a revisar sus prácticas crediticias, lo cual los hace más cautelosos a la hora de otorgar créditos.

- Nuevos estándares de riesgo de crédito asumidos por las entidades financieras.

- Los ajustes propiciados por una nueva normatividad y supervisión bancaria en torno al tema de la exposición al riesgo en el otorgamiento de nuevos créditos obligan a las entidades financieras a ser más cautelosas en su actividad crediticia y, con ello, a realizar mayores esfuerzos patrimoniales con el fin de llevar a cabo el saneamiento de sus balances. Esto se traduce en una menor disponibilidad de recursos prestables.

- La carga regulatoria. El sector financiero es, sin duda, uno de los agentes más regulados de una economía; los costos en los que se incurre por este concepto reducen la capacidad del sector de otorgar nuevos recursos por la vía del crédito.

- El valor real de las garantías. El papel de las garantías es crucial para hacer viable una operación de crédito. Por una parte, en caso de incumplimiento de una 
obligación, al haber garantías se reduce el riesgo de crédito de las entidades financieras; por otra, el peligro de perder la garantía en caso de incumplimiento incentiva al deudor a utilizar los recursos obtenidos en proyectos que sean más rentables y seguros (Urrutia, 2001). Un caso ilustrativo en este aspecto lo constituye el crédito hipotecario, cuyo estancamiento después de la crisis financiera obedeció en buena medida al deterioro de las garantías de finca raíz".

\subsection{Impago y racionamiento del crédito}

Una consecuencia del impago es el "racionamiento del crédito". Éste se refiere a una situación en la que al tipo de interés en la transacción del crédito, al prestatario le gustaría conseguir un préstamo pero no se lo permite el prestamista (p. 534).

Cuando un pequeño productor solicita un préstamo es porque sus beneficios no permiten cubrir los requerimientos de la inversión. Dado que los beneficios están definidos como la diferencia entre la producción y los costos de los préstamos, dicho valor estará determinando la restricción presupuestaria. Esta función está explicada a través de la siguiente ecuación:

Sea $f(L)-L(i+r) \geq B$ donde $f(L)$ corresponde al valor de la producción total y $(l)$ al monto del préstamo dada la tasa de interés $r$ y la restricción depende de los beneficios del proyecto $(B)$.

La función de producción estándar satisface las siguientes condiciones:

La productividad marginal del capital

$F^{1}()<$.0 y $F^{1}()<$.
La condición de maximización está dada por:

$\max L(L)-L(i+r)(10)$

La condición de primer orden se presenta como $\mathrm{F}^{1}\left(\mathrm{~L}^{*}\right)=(1+r)$

En este caso los productores no ahorran, ni acumulan, y tienen que financiar las necesidades de inversión en cada período.

Cuando aparecen $\mathrm{n}$ períodos la función multiplicada por $\mathrm{n}$ es equivalente a $\mathrm{n}[F(L)-L(1 * i)]$. Si el productor no decide devolver el crédito obtiene la cantidad $F(L)$ en su totalidad; por tanto, en el siguiente período el banco no vuelve a prestarle y obtiene $\mathrm{B}$ por período. De esta manera, el beneficio total obtenido en el horizonte de $\mathrm{n}$ períodos es $F(L)+(n-1) B$. Para que el usuario del crédito devuelva el préstamo se debe cumplir la siguiente condición: $n[F(L)-L(1+i)] \geq F(L)+(n-1) B$

Despejando B

$F(L)-\frac{\mathrm{n}}{\mathrm{n}-1} L(1+i) \geq B(11)$

La nueva restricción B es más restrictiva y se conoce como restricción de no impago; por tanto, entre más corto es el horizonte temporal más difícil es establecer la condición de no impago.

Una cuestión importante a tener en cuenta dentro del concepto de crédito racionado, es que el prestamista, cuando ocurre una posible situación de impago, no reacciona subiendo la tasa de interés, pues el miedo a que no le devuelvan los recursos impide que haga eso. Un préstamo mayor aumenta también el rendimiento que obtiene el prestatario que no devuelve el crédito, al permitirle embolsarse más dinero. Un tipo de interés más 
alto también aumenta el rendimiento al permitir que el prestatario que no devuelve el préstamo se ahorre el pago de intereses. Por tanto, el contrato que prefiere el prestamista implica, pues, el racionamiento del crédito.

En conclusión, simultáneo al crédito racionado se ha desarrollado el concepto del riesgo del prestamista, especialmente cuando ocurre situación de impago, pues la posibilidad de que el prestatario no devuelva el préstamo limita la concesión de nuevos préstamos en el futuro, principalmente cuando es voluntario, lo cual lleva a racionar los créditos.

Finalmente, el racionamiento de crédito puede estar asociado a la información asimétrica respecto a la tasa de interés, pues si esta es demasiado alta, genera el temor de atraer sólo prestatarios de alto riesgo. Por tanto, algunas teorías que explican las características de los créditos informales y su relación con el racionamiento se sustentan básicamente en el comportamiento de la tasa de interés como factor de riesgo e incumplimiento, así como las que consideran que el crédito es una excusa para transferir un garantía del prestamista al prestatario, situación que se da frecuentemente cuando los créditos son otorgados de manera informal.

El financiamiento de la inversión de una empresa depende de la disponibilidad de fondos internos (retención de utilidades) y externos (endeudamiento y emisión de acciones). En un mundo como el propuesto por Modigliani y Miller, en el que los mercados de capitales son perfectos, la decisión de a qué fuente de recursos acudir es irrelevante para la firma, dado que puede acceder con igual facilidad a cualquiera de ellas. Sin embargo, cuando hay asimetrías de información, costos de agencia y problemas en el cumplimiento de los contratos, estos mecanismos de obtención de recursos dejan de ser sustitutos perfectos, pues se generan diferenciales en los costos de acceso a dichos fondos.
Estos problemas han sido ampliamente identificados en la literatura. De hecho, Stiglitz y Weiss (1981), en uno de los trabajos más reconocidos dentro de esta línea de análisis, llegan al resultado de que cuando los mercados son imperfectos, los oferentes de recursos no pueden observar el retorno de los proyectos de inversión que indirectamente financian, y pueden darse equilibrios caracterizados por el racionamiento de crédito con considerables repercusiones sobre los niveles de inversión en la economía. Asimismo, dichas imperfecciones en los mercados de capitales también pueden conducir al establecimiento de diferenciales entre los costos de financiamiento con recursos externos e internos, de tal forma que el mayor costo sobre los fondos externos que tiene que enfrentar una firma depende directamente de sus condiciones financieras. Bernanke y Gertler (1989) construyen un modelo en el que dicho premium depende inversamente de los activos que el deudor puede proveer como garantía del crédito que está tomando; de esta manera, cuanto mayor sea la proporción del colateral sobre el crédito, menores son los incentivos del prestatario para embarcarse en proyectos riesgosos de inversión.

De este modo, cuando se incorpora la existencia de información asimétrica al modelaje de los mercados de capitales, las firmas no son indiferentes entre las alternativas de financiamiento de sus proyectos de inversión. Las imperfecciones en estos mercados imponen restricciones sobre los costos y disponibilidad de recursos externos a las empresas, de manera que las decisiones de inversión no sólo se toman con base en la senda óptima de capital de la firma como propone la teoría neoclásica, sino que también dependen de las posibilidades de financiamiento.

En consecuencia, el comportamiento inversor de la firma está sujeto a sus condiciones financieras, que determinan tanto el costo como el monto de los recursos externos a los que puede acceder. Tradicionalmente, los modelos 
basados en la ' $q$ ' de Tobin han constituido la aproximación más elemental, y en un comienzo más utilizada, para estudiar la importancia de las restricciones financieras a nivel de la firma. No obstante, éstos presentan serias limitaciones. Su principal inconveniente es que la $q$ promedio puede no ser una buena medida del precio sombra de una unidad adicional de capital, es decir, de las oportunidades de inversión de la firma. Lo anterior es particularmente cierto bajo condiciones de competencia imperfecta, como también cuando el capital no es un factor de producción cuasi-fijo, y los precios de las acciones responden a modas o tendencias pasajeras (Schiantarelli, 1996).

Schiantarelli, presenta una crítica revisión de la literatura empírica tanto para modelos de la $q$, como para enfoques basados en la ecuación de Euler. Si bien el autor encuentra que la segunda es una mejor aproximación, también señala ciertos inconvenientes asociados a la ecuación de Euler. De hecho, existe la posibilidad de que las restricciones financieras no sean detectadas cuando éstas son constantes en el tiempo. Otra dificultad es que los parámetros estimados mediante este enfoque son sensibles a la regla de normalización; no obstante, este problema suele presentarse en estimaciones con muestras pequeñas.

Una aproximación alternativa que supera dichas dificultades consiste en estimar la ecuación de Euler para la inversión, que se deriva del mismo problema de optimización de la $q$, y tiene la ventaja adicional de que no requiere medidas de rentabilidad basadas en información de mercados accionarios. La ecuación de Euler, cuyo marco teórico y metodológico se presenta en la próxima sección, establece que el costo marginal de invertir en el presente debe igualarse al costo marginal de posponer la decisión de inversión por un período más. Adicionalmente, permite relajar los supuestos sobre retornos constantes a escala y mercados de capitales perfectos, lo cual no sólo es una ventaja sobre la metodología de la $q$, sino que también ha permitido un mejor desempeño en las estimaciones dentro de la literatura empírica (Schiantarelli, 1996, pp. 70-89) .

\section{Créditos alternativos: teorías del mercado del crédito informal}

Numerosos estudios en algunos países han revelado que el mercado de créditos informal tiene características que difieren un poco de los préstamos convencionales. Los créditos son ofrecidos por particulares sobre la base de acuerdos verbales con pequeño o ningún colateral ${ }^{2}$, lo cual hace atractiva esta opción a corto plazo por su disponibilidad inmediata, aunque a largo plazo generan altos riesgos para los usuarios.

El mercado de crédito suele ser muy segmentado y definido para un mercado donde el prestamista tiene información preliminar sobre quiénes son sus posibles usuarios de crédito, pues muchas relaciones de crédito son personales y se tarda tiempo en establecerlas.

Existe una frecuente vinculación del mercado del crédito con otros mercados, tales como tierra, vivienda, mano de obra o cultivos. Las tasas de interés de los créditos informales son diferentes y varían según el lugar geográfico, el origen de los fondos y las características del préstamo. Generalmente, las tasas de interés ofrecidas son más altas que el promedio de las tasas de interés de los bancos y con una significativa dispersión, presentando aparentemente oportunidades de arbitraje.

La imposición de créditos racionados, limita el acceso a los préstamos para todos los solicitantes de créditos, es-

2 Colateral se define como aquella parte del valor del crédito que el prestatario deja como garantía al prestamista, para respaldar una obligación de deuda. 
pecialmente para aquellas personas de escasos recursos o pequeños empresarios, quienes tienes dificultades de ahorro. Además, los prestatarios no pueden pedir prestada la cantidad deseada; es decir, la cantidad máxima que recibe el usuario de crédito de un prestamista es limitada. Por ello, el racionamiento es un caso especial de exclusión donde algunos prestatarios quedan excluidos inmediatamente de las listas de clientes potenciales que poseen algunos acreedores.

Hay diferentes enfoques teóricos que intentan explicar algunas o todas estas características. Aunque difieren en los mecanismos específicos propuestos, la mayoría comparte un tema común: el crédito del mundo informal se explica por una pérdida de mercados, por problemas de información asimétrica, múltiples exigencias en las solicitudes, garantías reales y por falta de incentivos.

\subsection{El riesgo del prestamista en los créditos informales}

La hipótesis del riesgo del prestamista, según Bottomley (1975), sostiene que los prestamistas no obtienen un rendimiento (ex ante) por su dinero superior a su costo de oportunidad. Según esta hipótesis, en los mercados de crédito rural existe un elevado riesgo de que los prestatarios ni paguen los intereses ni devuelvan los créditos.

Existen dos tipos de riesgo: el primero es el riesgo de impago involuntario a causa de la mala suerte (desempleo, una mala cosecha o enfermedad, muerte, etc.), donde el prestatario puede no disponer de suficiente dinero cuando vence el préstamo; el segundo es el impago voluntario o estratégico, donde el prestatario puede obtener el dinero e irse o negarse a devolverlo.
Si existen dos probabilidades respecto al pago, $p$ de que el prestatario devuelva el dinero prestado y, caso contrario, $1-p$ de que no lo devuelva, al considerar a un prestamista representativo de una pequeña localidad dentro de un mercado competitivo presta una cantidad ${ }^{L}$ a una tasa de interés ${ }^{t}$ en el mercado competitivo informal $\mathrm{y}^{r}$ el costo de oportunidad de los fondos para cada prestamista, dado que sólo se devuelve una proporción de p de los préstamos.

El beneficio esperado del prestamista es (Debraj, 2002, pp. 529-531): $p(1+i) L-(1+r) L(7)$

En condiciones de equilibrio la condición de beneficio nulo implica que este valor debe ser cero.

$\mathrm{p}(1+\mathrm{i}) \mathrm{L}-(1+\mathrm{r}) \mathrm{L}=0(8)$

Despejando ${ }^{i}$ de la ecuación (8) la tasa de interés del mercado informal, esta se convierte en:

$i=\frac{(1+r)}{p}-1$

Por tanto, la tasa de interés del mercado informal (ecuación 9), está relacionada directamente con la tasa de interés del crédito bancario y de manera indirecta con la probabilidad de pago.

Cuando $\mathrm{p}=1$, es decir, no hay riesgo de impago, $i=r$, la tasa del sector informal es igual a la tasa del sector formal. Sin embargo, en el caso de que $\mathrm{p}<1$, es decir, la imposibilidad de impago se hace menor, entonces $i>r$, el tipo de interés informal es más alto para cubrir el riesgo de impago.

El temor a impago lleva también a pedir una garantía, siempre que sea posible. Esta puede adoptar muchas formas. Una es la transferencia de los derechos de propie- 
dad mientras esté vigente el préstamo. Otra forma son los ingresos laborales del prestatario. Existen unas garantías poco usuales; por ejemplo, en la India, donde existe una hipoteca de los derechos de usufructo, es decir, se cede los derechos de propiedad de la producción del agricultor mientras dure la obligación (Kurup, 1976).

Debraj considera dos tipos de garantía: en la primera, tanto el prestamista como el prestatario valoran mucho la garantía; en la segunda, el prestatario la valora pero el prestamista no. Desde el punto de vista de impago estratégico, da lo mismo que se utilice el primer tipo de garantía o el segundo. Esta situación ha permitido explicar el punto de vista de que el crédito es una excusa para transferir una garantía del usuario del crédito a los prestamistas, situación que se presenta frecuentemente cuando los préstamos son informales.

\section{La restricción de crédito en Colombia}

En economías con mercados de capitales poco desarrollados como Colombia, el sistema bancario es el principal proveedor de créditos a los hogares y a las empresas, convirtiéndose así en un agente central para la actividad productiva. Es así como un racionamiento de crédito puede causar un deterioro en la actividad económica.

Esto puede suceder en periodos de condiciones monetarias restrictivas, durante crisis financieras, o, de manera permanente, en caso de que los precios sean demasiado rígidos, como en países con controles a las tasas de interés. En Colombia se han dado estas características: hay límites para algunas tasa de interés, y a finales de los noventa se experimentó una crisis financiera que estuvo acompañada por una política monetaria contraccionista.
La combinación de la desaceleración de la demanda y la disminución en la actividad del sector real puede conducir a una contracción de la oferta crediticia. Según los resultados a diciembre de la Encuesta sobre la situación del crédito en Colombia del Banco de la República, los bancos comerciales manifestaron que esperaban una restricción en la oferta crediticia y un aumento en las exigencias para otorgar crédito, especialmente en las carteras de consumo y comercial.

\subsection{Resultados de la investigación}

El menor dinamismo del sistema financiero durante 2008 estuvo acompañado de un incremento en los riesgos potenciales y de la materialización de algunos: en el caso del riesgo de crédito, el incremento en la cartera vencida evidencia la materialización del mismo, a la vez que la aceleración de la riesgosa aumenta el riesgo potencial para 2009. El crecimiento acelerado de los créditos desde 2006 permitió la entrada de deudores más riesgosos al sistema financiero, especialmente en la modalidad de consumo, aumentando el índice de calidad de cartera y el de morosidad (Banco de la República, 2009). En el caso particular de la cartera de consumo, la reducción en el ritmo de crecimiento de la economía explica el mal comportamiento de su calidad a finales de 2008 (tabla 2).

En el caso de la cartera comercial, el comportamiento observado desde 2006 sugiere que hay una desaceleración, que se tradujo en una tasa de crecimiento real anual de $20 \%$ en diciembre de 2008 y un crecimiento de apenas el $2 \%$ a diciembre del 2009, significativamente inferior a la cifra observada dos años atras (25\%). Respecto a la cartera de consumo el comportamiento fue similar, registrándose un crecimiento también del 2\% para el año de 2009 (tabla 1). Por otro lado, según la encuesta trimestral de expectativas económicas que el Banco de la República 
realiza a un grupo de empresas en Colombia, el porcentaje de encuestados que percibe que la disponibilidad de crédito es alta ha disminuido, y sigue una tendencia similar a la observada en el crecimiento de la cartera comercial.

Lo anterior sólo da indicios de una desaceleración de la actividad crediticia, mas no permite responder a la pregunta de si existe o no racionamiento. Como los agregados son el resultado de la interacción entre la demanda y la oferta de crédito, una disminución en la cantidad otorgada puede estar mostrando tanto una reducción en la cantidad demandada como una menor disposición de los bancos a conceder préstamos. Las restricciones al endeudamiento varían con las características propias de las empresas y con los factores del ciclo económico, dando así la posibilidad de que empresas que están restringidas en un año no necesariamente lo estén en otro (Corredor Waldron y Pérez Reina, 2009).

En Colombia, el mercado de crédito a través del sistema financiero tradicional, se ha caracterizado por ser imperfecto, dado que hay racionamiento de recursos para atender las necesidades de capital de trabajo y capital de los pequeños productores (formales e informales). Adicionalmente, es incompleto por no atender a un amplio segmento de la población de escasos recursos. El problema de otorgar recursos para este tipo de créditos son los perfiles de los usuarios como microempresarios y población muy vulnerable y con altos riesgos de no pago. Sólo algunas entidades financieras ofrecen estas líneas de créditos (BBVA, Bancolombia, Banagrario, Banco Caja Social) y las compañías de financiamiento comercial como Finamérica y Compartir. También existen en el país muchas fundaciones especializadas en microcrédito y algunas entidades cooperativas.

Tabla 1. Evolución de saldos de cartera bruta sistema financiero en Colombia (millones de pesos al mes de diciembre de cada año)

Cartera Bruta Sistema Financiero 2002-2010.

\begin{tabular}{|c|c|c|c|c|c|c|c|c|c|}
\hline & dic-02 & dic-03 & dic-04 & dic- -05 & dic-06 & dic- -07 & dic-08 & dic-09 & nov-10 \\
\hline Comercial Bruto & 39.447 .677 & 42.830 .022 & 52.390 .453 & 57.132 .808 & 71.602 .813 & 89.473 .141 & 107.042 .827 & 108.686 .695 & 123.810 .583 \\
\hline $\begin{array}{l}\text { Consumo } \\
\text { Bruto }\end{array}$ & 8.117 .776 & 9.878 .648 & 13.028.206 & 18.032.372 & 26.863 .563 & 36.44 & 40.805 .044 & 41.3 & 47.26 \\
\hline Vivienda Bruta & 12.451 .701 & 11.127 .544 & 8.528 .773 & 8.311 .865 & 9.181 .403 & 10.963 .792 & 12.284 .108 & 13.582 .589 & 16.173 .321 \\
\hline Microcrédito Bruto & 391.250 & 570.520 & 844.147 & 1.257 .790 & 1.684 .349 & 1.981 .994 & 3.087 .976 & 3.842 .417 & 4.261 .636 \\
\hline Total & 60.408 .404 & 64.406 .733 & 74.791 .580 & 84.734 .835 & 109.332.12 & 138.864 .068 & 163.219 .956 & 167.506 .443 & 191.513 .40 \\
\hline
\end{tabular}


Porcentaje de crecimiento de cartera bruta sistema financiero 2002-2010

\begin{tabular}{|c|c|c|c|c|c|c|c|c|c|}
\hline & dic-02 & dic-03 & dic-04 & dic- 05 & dic-06 & dic- -07 & dic- 08 & dic-09 & nov-10 \\
\hline Comercial Bruto & & $9 \%$ & $22 \%$ & $9 \%$ & $25 \%$ & $25 \%$ & $20 \%$ & $2 \%$ & $14 \%$ \\
\hline Consumo Bruto & & $22 \%$ & $32 \%$ & $38 \%$ & $49 \%$ & $36 \%$ & $12 \%$ & $1 \%$ & $14 \%$ \\
\hline Vivienda Bruta & & $-11 \%$ & $-23 \%$ & $-3 \%$ & $10 \%$ & $19 \%$ & $12 \%$ & $11 \%$ & $19 \%$ \\
\hline Microcredito Bruto & & $46 \%$ & $48 \%$ & $49 \%$ & $34 \%$ & $18 \%$ & $56 \%$ & $24 \%$ & $11 \%$ \\
\hline Total & & $7 \%$ & $16 \%$ & $13 \%$ & $29 \%$ & $27 \%$ & $18 \%$ & $3 \%$ & $14 \%$ \\
\hline
\end{tabular}

Participación carteras sobre cartera total sistema financiero

\begin{tabular}{llllllllll}
\hline Comercial Bruto & $65 \%$ & $66 \%$ & $70 \%$ & $67 \%$ & $65 \%$ & $64 \%$ & $66 \%$ & $65 \%$ & $65 \%$ \\
\hline Consumo Bruto & $13 \%$ & $15 \%$ & $22 \%$ & $21 \%$ & $25 \%$ & $26 \%$ & $25 \%$ & $25 \%$ & $25 \%$ \\
\hline Vivienda Bruta & $21 \%$ & $17 \%$ & $14 \%$ & $10 \%$ & $8 \%$ & $8 \%$ & $8 \%$ & $8 \%$ & $8 \%$ \\
\hline Microcrédito Bruto & $1 \%$ & $1 \%$ & $1 \%$ & $1 \%$ & $2 \%$ & $1 \%$ & $2 \%$ & $2 \%$ & $2 \%$
\end{tabular}

Fuente: Recuperado el 28 de febrero de 2011 desde <http:/www.superfinanciera.gov.com>

Con respecto al comportamiento de la cartera de todo el sistema financiero en Colombia durante el período 2002-2010, se observa que los créditos de mayor participación en la cartera total durante el año 2010 son el comercial y el de consumo con el $61 \%$ y el 25\% respectivamente y el de menor los microcréditos con apenas el 2\% (tabla 1). Lo anterior demuestra que la mayoría de recursos otorgados por el sistema financiero se efectúa de manera restrictiva, que para el caso de los créditos comercial y de consumo, exigen como requisitos: ingresos de los clientes, certificados laborales, ingresos y retenciones, extractos de cuentas bancarias y autorización para consultar en centrales de riesgo. De otro lado, los microcréditos que otorgan las entidades financieras exigen menos requisitos, pero se orientan principalmente a personas que tienen empresas o ideas de negocio claras. Entre este público se cuentan los ciudadanos que cumplen con los requisitos del Banco de las Oportunidades y quienes, por algún motivo, no pueden acceder a estos créditos y necesitan del apoyo o la asesoría de estas entidades.

Tabla 2. Evolución cartera total y cartera vencida sistema financiero 2002-2010 (millones de pesos)

Cifras con corte a 16-dic-2010

\begin{tabular}{|c|c|c|c|c|c|c|c|c|c|}
\hline & dic-02 & dic-03 & dic-04 & dic-05 & dic-06 & dic-07 & dic-08 & dic-09 & nov-10 \\
\hline $\begin{array}{l}\text { Comercial } \\
\text { Bruto }\end{array}$ & 39.447 .677 & 42.830 .022 & 52.390 .453 & 57.132 .808 & 71.602 .813 & 89.473 .141 & 107.042 .827 & 108.686 .695 & 123.810 .583 \\
\hline $\begin{array}{l}\text { Comercial } \\
\text { Vigente }\end{array}$ & 37.835 .057 & 41.528 .070 & 51.078 .269 & 56.246 .936 & 70.567 .519 & 87.762 .782 & 104.377 .316 & 105.526 .811 & 120.898 .257 \\
\hline $\begin{array}{l}\text { Comercial } \\
\text { Vencido }\end{array}$ & 1.612 .620 & 1.301 .952 & 1.312 .184 & 885.872 & 1.035.294 & 1.710 .360 & 2.665 .511 & 3.159 .885 & 2.912 .326 \\
\hline
\end{tabular}


Las imperfecciones del mercado de créditos, la restricción crediticia y los créditos alternativos Gustavo Adolfo Díaz Valencia

\begin{tabular}{llllllllllll} 
& dic-02 & dic-03 & dic-04 & dic-05 & dic-06 & dic-07 & dic-08 & dic-09 & nov-10 \\
$\begin{array}{l}\text { Consumo } \\
\text { Bruto }\end{array}$ & 8.117 .776 & 9.878 .648 & 13.028 .206 & 18.032 .372 & 26.863 .563 & 36.445 .141 & 40.805 .044 & 41.394 .742 & 47.267 .953 \\
$\begin{array}{l}\text { Consumo } \\
\text { Vigente }\end{array}$ & 7.633 .635 & 9.374 .319 & 12.479 .568 & 17.333 .264 & 25.662 .012 & 34.403 .030 & 37.864 .530 & 38.701 .978 & 44.851 .971 \\
$\begin{array}{l}\text { Consumo } \\
\text { Vencido }\end{array}$ & 484.141 & 504.329 & 548.638 & 699.108 & 1.201 .551 & 2.042 .111 & 2.940 .514 & 2.692 .764 & 2.415 .981 \\
& & & & & & & & & & & \\
\hline $\begin{array}{l}\text { Vivienda } \\
\text { Bruta }\end{array}$ & 12.451 .701 & 11.127 .544 & 8.528 .773 & 8.311 .865 & 9.181 .403 & 10.963 .792 & 12.284 .108 & 13.582 .589 & 16.173 .321 \\
$\begin{array}{l}\text { Vivienda } \\
\text { Vigente }\end{array}$ & 9.339 .976 & 8.385 .258 & 7.489 .254 & 7.626 .136 & 8.602 .114 & 10.372 .115 & 11.664 .671 & 12.937 .329 & 15.515 .388 \\
$\begin{array}{l}\text { Vivienda } \\
\text { Vencido }\end{array}$ & 3.111 .725 & 2.742 .286 & 1.039 .520 & 685.729 & 579.289 & 591.677 & 619.437 & 645.260 & 657.933 \\
\hline $\begin{array}{l}\text { Microcrédito } \\
\text { Bruto }\end{array}$ & 391.250 & 570.520 & 844.147 & 1.257 .790 & 1.684 .349 & 1.981 .994 & 3.087 .976 & 3.842 .417 & 4.261 .636 \\
\hline $\begin{array}{l}\text { Microcrédito } \\
\text { Vigente }\end{array}$ & 365.513 & 539.971 & 798.534 & 1.199 .618 & 1.592 .447 & 1.841 .813 & 2.895 .339 & 3.618 .563 & 4.044 .553 \\
\hline $\begin{array}{l}\text { Microcrédito } \\
\text { Vencido }\end{array}$ & 25.737 & 30.549 & 45.613 & 58.171 & 91.902 & 140.181 & 192.636 & 223.853 & 217.083 \\
\hline
\end{tabular}

Porcentaje de cartera vigente y cartera vencida créditos sistema financiero

\begin{tabular}{|c|c|c|c|c|c|c|c|c|c|}
\hline & dic-02 & dic-03 & dic-04 & dic-05 & dic-06 & dic- -07 & dic-08 & dic-09 & nov- 10 \\
\hline \multicolumn{10}{|l|}{ Comercial Bruto } \\
\hline Comercial Vigente & $95,9 \%$ & $97,0 \%$ & $97,5 \%$ & $98,4 \%$ & $98,6 \%$ & $98,1 \%$ & $97,5 \%$ & $97,1 \%$ & $97,6 \%$ \\
\hline Comercial Vencido & $4,1 \%$ & $3,0 \%$ & $2,5 \%$ & $1,6 \%$ & $1,4 \%$ & $1,9 \%$ & $2,5 \%$ & $2,9 \%$ & $2,4 \%$ \\
\hline \multicolumn{10}{|l|}{ Consumo Bruto } \\
\hline Consumo Vigente & $94,0 \%$ & $94,9 \%$ & $95,8 \%$ & $96,1 \%$ & $95,5 \%$ & $94,4 \%$ & $92,8 \%$ & $93,5 \%$ & $94,9 \%$ \\
\hline Consumo Vencido & $6,0 \%$ & $5,1 \%$ & $4,2 \%$ & $3,9 \%$ & $4,5 \%$ & $5,6 \%$ & $7,2 \%$ & $6,5 \%$ & $5,1 \%$ \\
\hline \multicolumn{10}{|l|}{ Vivienda Bruta } \\
\hline Vivienda Vigente & $75,0 \%$ & $75,4 \%$ & $87,8 \%$ & $91,7 \%$ & $93,7 \%$ & $94,6 \%$ & $95,0 \%$ & $95,2 \%$ & $95,9 \%$ \\
\hline Vivienda Vencido & $25,0 \%$ & $24,6 \%$ & $12,2 \%$ & $8,3 \%$ & $6,3 \%$ & $5,4 \%$ & $5,0 \%$ & $4,8 \%$ & $4,1 \%$ \\
\hline \multicolumn{10}{|l|}{ Microcrédito Bruto } \\
\hline Microcrédito Vigente & $93,4 \%$ & $94,6 \%$ & $94,6 \%$ & $95,4 \%$ & $94,5 \%$ & $92,9 \%$ & $93,8 \%$ & $94,2 \%$ & $94,9 \%$ \\
\hline Microcrédito Vencido & $6,6 \%$ & $5,4 \%$ & $5,4 \%$ & $4,6 \%$ & $5,5 \%$ & $7,1 \%$ & $6,2 \%$ & $5,8 \%$ & $5,1 \%$ \\
\hline
\end{tabular}

Fuente: recuperado el 28 de enero de 2011 desde <http:/www.superfinanciera.gov.co> 
$\mathrm{Al}$ considerar la cartera vigente y la cartera vencida, se observa que a noviembre del año 2010 los mayores índices de vencimiento los presentan los créditos de consumo y microcréditos, con el 5.1\%; sin embargo, esta cifra resulta significativa para la cartera de microcréditos, dado que su participación es menor respecto al total del sistema financiero y donde se pueden presentar problemas de impago por parte de los usuarios de estos créditos, dadas las altas tasas de interés que manejan. Los créditos comerciales son los que presentan el menor índice a esta fecha con el 2,4\%.

Tabla 3. Total cartera créditos y tasas de interés 2002-2010

Cifras en miles de pesos y tasas efectivas anuales

\begin{tabular}{|c|c|c|c|c|c|c|c|c|}
\hline \multirow[t]{2}{*}{ Fecha } & \multicolumn{2}{|c|}{ Créditos de Consumo } & \multicolumn{2}{|c|}{ Microcrédito } & \multicolumn{2}{|c|}{ Crédito Ordinario } & \multicolumn{2}{|c|}{ Tarjeta de Crédito } \\
\hline & Tasa & Monto & Tasa & Monto & Tasa & Monto & Tasa & Monto \\
\hline dic-02 & 26,94 & 470.399 .705 & 26,59 & 13.797 .698 & 16,48 & 1.323 .346 .329 & 28,84 & 552.304 .397 \\
\hline dic-03 & 26,74 & 606.137 .581 & 27,74 & 19.558 .121 & 16,49 & 2.001 .195 .999 & 28,89 & 804.671 .747 \\
\hline dic-04 & 24,93 & 999.910 .108 & 27,60 & 35.073 .242 & 16,83 & 2.552 .410 .798 & 28,18 & 962.359 .246 \\
\hline dic-05 & 22,65 & 1.010 .512 .078 & 24,48 & 37.814 .885 & 15,65 & 1.825 .599 .244 & 25,19 & 942.705 .974 \\
\hline dic-06 & 19,57 & 1.479 .306 .525 & 21,62 & 52.372 .141 & 13,83 & 3.282 .560 .504 & 22,02 & 1.209 .849 .799 \\
\hline dic-07 & 25,21 & 1.582 .609 .348 & 31,13 & 65.841 .064 & 17,23 & 4.273 .230 .086 & 30,33 & 1.487.270.705 \\
\hline dic-08 & 25,59 & 1.559.715.545 & 26,73 & 199.443 .252 & 17,48 & 8.453 .353 .955 & 30,95 & 1.847.523.528 \\
\hline dic-09 & 20,43 & 2.048.682.403 & 30,59 & 134.438 .758 & 12,12 & 8.464 .765 .538 & 25,48 & 2.006 .155 .555 \\
\hline nov-10 & 16,79 & 2.219 .861 .990 & 31,31 & 143.980 .745 & 10,84 & 6.710 .601 .296 & 21,01 & 1.771 .993 .467 \\
\hline
\end{tabular}

Total establecimientos de crédito

\begin{tabular}{|c|c|c|c|c|c|c|c|c|c|}
\hline \multirow{3}{*}{ Fecha } & \multicolumn{4}{|c|}{ Créditos de Vivienda en U.V.R. (Puntos) } & \multicolumn{4}{|c|}{ Créditos de Vivienda en Pesos } & \multirow{3}{*}{$\begin{array}{l}\text { Total } \\
\text { Desembolsos } \\
\text { Monto }\end{array}$} \\
\hline & & V.I.S. & & No V.I.S. & & V.I.S. & & No V.I.S. & \\
\hline & Tasa & Monto & Tasa & Monto & Tasa & Monto & Tasa & Monto & \\
\hline dic-02 & 11,00 & 48.504 .304 & 13,61 & 49.396 .410 & 16,08 & 67.700 & 16,08 & 1.275 .422 & 9.723 .923 .842 \\
\hline dic-03 & 10,90 & 48.721 .844 & 13,30 & 87.242 .763 & 16,08 & 71.900 & 19,51 & 8.010 .287 & 12.297 .550 .621 \\
\hline dic-04 & 10,51 & 68.995 .208 & 11,60 & 113.882 .747 & 16,08 & 1.276 .202 & 19,03 & 27.314 .240 & 15.294.193.711 \\
\hline dic-05 & 9,65 & 52.149 .472 & 10,01 & 104.816 .138 & 12,31 & 2.223 .535 & 18,42 & 51.852 .769 & 13.890 .660 .541 \\
\hline dic-06 & 7,63 & 60.600 .367 & 7,10 & 145.916 .754 & 13,28 & 44.768 .785 & 13,91 & 221.924 .773 & 20.008.897.118 \\
\hline dic- 07 & 9,97 & 50.008 .648 & 9,49 & 149.674 .151 & 15,65 & 56.525 .338 & 15,91 & 209.849.733 & 24.673 .610 .969 \\
\hline dic-08 & 9,92 & 40.971 .850 & 9,18 & 137.759 .420 & 17,07 & 49.208 .554 & 17,22 & 207.847 .925 & 29.910.374.172 \\
\hline dic-09 & 8,80 & 51.776 .252 & 7,76 & 151.844 .095 & 13,53 & 88.476 .387 & 14,00 & 462.976 .720 & 35.570 .215 .132 \\
\hline nov-10 & 6,77 & 65.092 .006 & 7,85 & 94.050 .480 & 12,68 & 92.407 .245 & 12,77 & 334.452 .143 & 30.101 .751 .691 \\
\hline
\end{tabular}

Fuente: recuperado el 28 de enero de 2011 desde <http:/www.superfinanciera.gov.co> 
A noviembre de 2010, las mayores tasas de interés son cobradas por el crédito de microfinanzas con el 31,31\%, las menores fueron para los créditos de vivienda de interés social (VIS) en puntos con el 6,77\% y diferente de VIS 7,85\%, las cuales fueron financiadas por el gobierno (tabla 3). Lo anterior refleja que los créditos microfinancieros otorgados por las entidades financieras, aunque buscan apoyar a pequeños productores y emprendedores, aún mantienen restricciones, por cuanto las tasas de interés, así como los altos costos financieros que asumen las entidades financieras por colocar estos recursos, se incluyen en el valor de la tasa. Estos aspectos limitan el acceso a dichos recursos a las personas de bajos ingresos que requieran apoyo para cubrir sus principales necesidades de financiación y fomentan aún más la informalidad crediticia.

Tabla 4. Comparación créditos formales e informales en Colombia 2007

Hogares que han tenido crédito alguna vez

\begin{tabular}{|c|c|c|c|c|}
\hline & Hogares & Microempresas & $\%$ Hogares & \% Microempresas \\
\hline Crédito Formal Comercial & $4.488 .994,00$ & $6.712 .369,00$ & $64 \%$ & $42 \%$ \\
\hline Crédito Formal Financiero & $3.303 .332,00$ & $854.368,00$ & $47 \%$ & $53 \%$ \\
\hline Crédito Informal & $5.666 .787,00$ & $947.436,00$ & $81 \%$ & $59 \%$ \\
\hline Total & $6.882 .884,00$ & $1.341 .397,00$ & $98 \%$ & $84 \%$ \\
\hline
\end{tabular}

Hogares que tienen crédito actualmente

\begin{tabular}{lllll} 
& Hogares & Microemresas & \% Hogares & \% Microempresas \\
\hline Crédito Formal Comercial & 2.223 .619 & 445.889 & $32 \%$ & $28 \%$ \\
\hline Crédito Formal Financiero & 1.853 .064 & 621.047 & $26 \%$ & $39 \%$ \\
\hline Crédito Informal & 2.463 .407 & 412.940 & $35 \%$ & $26 \%$ \\
\hline Total & 4.642 .762 & 1.002 .180 & $66 \%$ & $63 \%$
\end{tabular}

- Crédito informal: crédito con prestamistas (gota a gota), amigos, vecinos o familiares y casas de empeño.

- Crédito formal comercial: crédito con establecimientos de comercio, tendero, proveedor y empresa en donde algún miembro del hogar trabaja.

- Crédito formal financiero: crédito con bancos, cajas de compensación, fundaciones y cooperativas. 
Valor del crédito que tiene actualmente

\begin{tabular}{|c|c|c|c|c|}
\hline & Hogares (Bill) & Empresas (Bill) & Hogares $\%$ & Microempresas $\%$ \\
\hline Grédito Formal Comercial & 2,8 & 0,8 & $17 \%$ & $14 \%$ \\
\hline Credito Formal Financiero & 12,5 & 3,7 & $75 \%$ & $66 \%$ \\
\hline Crédito Informal & 1,3 & 1,1 & $8 \%$ & $20 \%$ \\
\hline Total & 16,6 & 5,6 & $100 \%$ & $100 \%$ \\
\hline
\end{tabular}

En términos del monto total del crédito la concentración en fuentes informales es mucho menor que en términos del total de hogares o microempresas con este tipo de crédito; sin embargo, el crédito informal es de menor plazo y mayor rotación.

Fuente: Encuesta de crédito informal en Colombia 2007. Econométrica S.A., Programa MIDAS

De acuerdo a un estudio efectuado por Econométrica en el año 2007 para hogares de estratos 1, 2 y 3 (600 encuestas) cuyo universo es de aproximadamente 7 millones, el 97\% se encuentran en municipios con presencia de entidades financieras y el $80 \%$ se encuentran en municipios urbanos.

Para el caso de las microempresas, las encuestadas (600 empresas) en este estudio son representativas de 1 millón seiscientas mil empresas ubicadas en los estratos 1,2 y 3 , de lo que se estima que es el universo a nivel nacional. Por tanto, 7 millones de hogares y 1.6 millones de microempresas se encuentran en los estratos 1, 2 y 3 .

Actualmente, el 35\% de los hogares y el 26\% de las empresas poseen crédito informal. El 26\% de los hogares y el 39\% de las empresas tienen crédito formal financiero. Sin embargo, los mayores montos de financiación se observan en los créditos formales con el sector financiero (tabla 4). Según este estudio, el 69\% de los hogares y el 50\% de las empresas combinan créditos formales e informales. De otra parte, se demostró que a mayor capacidad económica del hogar tanto hogares como empresas utilizan más crédito formal a través de bancos, cooperativas y establecimientos de comercio. El crédito formal se utiliza para proyectos de largo plazo, mientras el crédito informal se utiliza a corto plazo.

Para los hogares, la fuente de crédito más utilizada son amigos, vecinos y familiares, mientras la más oportuna pero la más costosa, son los prestamistas y casas de empeño. Los bancos otorgan préstamos de mayor plazo, pero son más demorados en el desembolso, con mayores costos de financiación y requisitos exigidos para su colocación, lo cual limita el acceso a estos recursos especialmente para las familias de estratos 1 y 2.

Las fuentes de crédito informal más utilizadas por los hogares de los estratos 1, 2 y 3 son en su orden las siguientes: amigos, vecinos y familiares, prestamistas, tenderos, empresas donde trabaja y casas de empeño. Mientras dentro de las formales se encuentran bancos, cooperativas, ONG financieras y cajas de compensación, siendo estas las menos utilizadas por los hogares seleccionados (figura 3). 


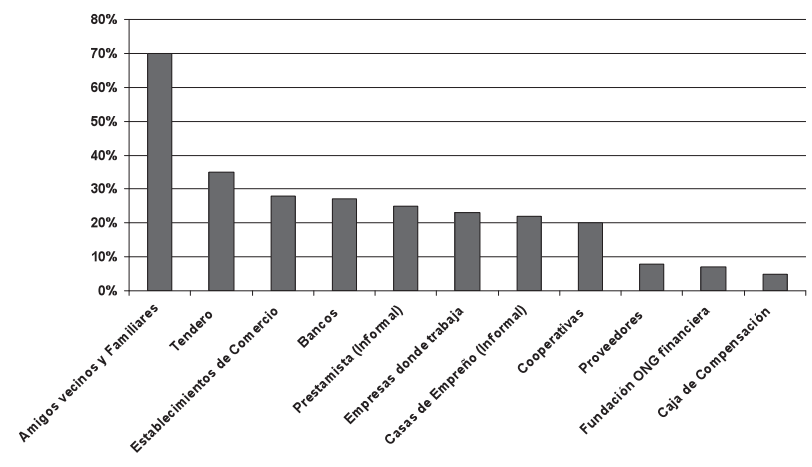

Figura 3. Fuentes de financiación de los hogares - 2007

Fuente: Encuesta de mercado de crédito informal, realizada por Econométrica S.A. (2007)

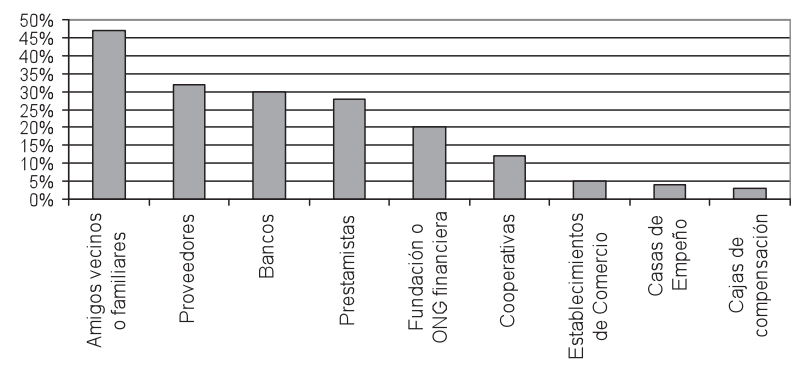

Figura 4. Fuentes de financiación de las empresas - 2007

Fuente: Encuesta de mercado de crédito informal, realizada por Econométrica S.A. (2007)

Para el caso de las microempresas (estratos 1, 2 y 3), la mayor fuente de financiación proviene de créditos informales otorgados por amigos, vecinos y familiares, mientras que los proveedores y bancos son la fuente de financia- ción formal más importante. La proporción de empresas que acceden al crédito formal es mayor al aumentar el estrato. De otra parte, las empresas formales tienden a financiarse más con los bancos y los proveedores.

Tabla 5. Promedio de tasas de interés cobradas por intermediarios financieros en Colombia - 2007

\begin{tabular}{|lll|}
\hline & Hogares & Microempresas \\
\hline Bancos & $20,98 \%$ & $24,14 \%$ \\
\hline Fundaciones & $20,73 \%$ & $17,30 \%$ \\
\hline Cooperativas & $22,78 \%$ & $24,77 \%$ \\
\hline Proveedor & 0 & $55,08 \%$ \\
\hline Amigos, vecinos, familiares & $68,25 \%$ & $78,26 \%$ \\
\hline Casa de empeño & $213,84 \%$ & $213,84 \%$ \\
\hline Prendería & $279,98 \%$ & $274,70 \%$ \\
\hline
\end{tabular}

Los bancos, cooperativas y fundaciones, los de menor tasa.

La empresa donde trabaja, amigos, familiares o vecinos y proveedor le siguen.

Los más costosos son los prestamistas y las casas de empeño.

Fuente: Encuesta de crédito informal en Colombia 2007. Econométrica S.A., Programa MIDAS.

Una de las variables que más ocasionan restricción crediticia son las tasas de interés. Para el año 2007, la Encuesta de crédito informal demostró que las mayores tasas de interés son las cobradas por los créditos informales, otorgados por prenderías y casas de empeño. Aunque estos recursos se entregan inmediatamente, los usuarios corren el riesgo de perder sus inmuebles. De otra parte, las tasas más bajas son cobradas por fundaciones y bancos, pero los recursos son entregados con mayores limitaciones y en períodos más largos que tardan hasta más de tres meses, y con costos financieros elevados (tabla 5). 


\section{Créditos alternativos en Colombia}

En Colombia se han desarrollado mecanismos de financiación que en cierta medida facilitan la disponibilidad de recursos a los empresarios y microempresarios; sin embargo, estos recursos no llegan a todos. Existen los créditos de fomento manejados con recursos de redescuento, que administra la banca de segundo piso (Finagro, Bancoldex, IFI, Findeter), para impulsar el desarrollo de actividades productivas como la industria, el comercio, la agricultura, la minería y cuya financiación se hace en condiciones especiales que en primera instancia facilitan el compromiso financiero. En otros casos estos recursos son amparados por Fondos de Garantías para el caso de productores agrícolas e industriales y a partir del 2002 algunas entidades financieras están ofreciendo los microcréditos.

El microcrédito como una línea de crédito dirigida a financiar a microempresarios y personas con bajos recursos se definió a través del artículo 39 de la Ley 590 de 2000 y la Circular Externa 50 de 2001 recoge la definición de microcrédito y la establece como modalidad del Plan Único de Cuentas, brindándole la opción al sistema financiero para atender a dicho segmento de clientes.

Artículo 39. Sistemas de microcrédito. Con el fin de estimular las actividades de microcrédito, entendido como el sistema de financiamiento a microempresas, dentro del cual el monto máximo por operación de préstamo es de veinticinco (25) salarios mínimos mensuales legales vigentes sin que, en ningún tiempo, el saldo para un solo deudor pueda sobrepasar dicha cuantía autorizase a los intermediarios financieros y a las organizaciones especializadas en crédito microempresarial, para cobrar honorarios y comisiones, de conformidad con las tarifas que autorice el
Consejo Superior de Microempresa, no repuntándose tales cobros como intereses, para efectos de lo estipulado en el artículo 68 de la Ley 45 de 1990³.

En Colombia, a partir de 2002 se ha venido implementando una actividad financiera denominada microcrédito, como una forma de apoyo a los sectores de escasos recursos y en cierta medida como una manera de contrarrestar los créditos racionados del sector financiero tradicional. Estos créditos han sido liderados por las ONG y fundaciones sin ánimo de lucro, convirtiendo a estos sectores en entidades crediticias reguladas por la superintendencia bancaria.

Algunas entidades bancarias otorgan estos créditos utilizando la figura de corresponsales no bancarios para llegar a la población objetivo. Estas son las personas de bajos recursos, quienes tradicionalmente no son sujetos de préstamos. Los corresponsales de créditos son una figura aprobada por el gobierno (Decreto 2233 del 7 de julio de 2006), mediante la cual los bancos pueden utilizar establecimientos como droguerías, tiendas de barrio, entre otros, para prestar sus servicios a poblaciones alejadas.

A pesar de que para el año 2008 el acceso a los servicios generales alcanzó un $55.9 \% \%^{4}$, representando un incremento importante frente al año 2002 que fue de 39\%, sólo el $23.2 \%$ de la población tiene acceso a un producto de crédito (tarjetas de crédito, créditos de libre inversión). Entre las causas que pueden ocasionar el limitado acceso a recursos financieros se destacan las siguientes: las restricciones originadas por tipos de agente y por barreras institucionales (Uribe, 2009).

3 Ley 590 de 2000, Julio 10. Congreso de la República. Promoción del Desarrollo de las micro, pequeñas y medianas empresas. Capítulo I.

4 Reporte de Bancarización de la Asociación Bancaria (Asobancaria), diciembre de 2008. 
Dentro del grupo de restricciones originadas por tipo de agente se encuentran aquellos individuos excluidos tanto de manera voluntaria como involuntaria. Se argumenta que la principal razón de autoexclusión obedece a la falta de conocimiento de los productos y servicios financieros, así como sus requisitos, principalmente en grupos poblacionales del sector rural. Por otra parte, los excluidos involuntariamente no cumplen con los requisitos necesarios para acceder a los créditos por ubicación geográfica, por motivos de riesgo y asimetrías de información.

Las barreras institucionales están relacionadas con restricciones que imponen los intermediarios financieros para acceder a dichos recursos, entre ellos exigencias en cuanto a montos mínimos para apertura de depósitos de ahorro, altas cuotas de manejo y administración de líneas de crédito y de ahorro.

La poca atención que ha tenido el sector microfinanciero en Colombia, podría explicarse por diferentes razones. La primera razón tiene que ver con los factores que dificultan el acceso de los microempresarios colombianos urbanos a estos servicios, entre los cuales pueden citarse la incertidumbre económica, la debilidad patrimonial de los microempresarios, la falta de formalidad y de registros contables de sus negocios y la carencia de garantías. Adicionalmente, los microempresarios, especialmente los informales, son considerados de alto riesgo crediticio porque no existe un sistema de información sobre el riesgo del sector, ni entidades que soporten la evaluación y seguimiento de los potenciales clientes para el sistema financiero.

En particular, las garantías de crédito son barreras infranqueables debido a que los micro y los pequeños empresarios no disponen de inmuebles o propiedades para otorgar como garantía real. En caso afirmativo, las garantías no permiten conseguir préstamos adicionales, y la banca sólo acepta excepcionalmente los estudios de pre inversión como garantía de crédito (Pino Hidalgo, 2002).

Si bien las microempresas formales ${ }^{5}$ logran alcanzar niveles de productividad y de rentabilidad que les permiten absorber los costos de acceso a la legalidad y pagar salarios aceptables, muchas de las microempresas informales y los trabajadores por cuenta propia enfrentan, por el contrario, grandes dificultades para mantenerse en el mercado puesto que las ramas en las que operan se encuentran deprimidas por la saturación de la oferta, la competencia de artículos importados o producidos localmente en empresas más eficientes o por los cambios en los patrones de consumo de la población. Por tanto, les resulta difícil encontrar demanda para los bienes y servicios que ofrecen (OIT, 1999, p. 13). Es por ello que para estos grupos de productores, la financiación constituye una salida viable para responder a los retos que impone el desarrollo de sus actividades económicas.

Sin embargo, a pesar de existir opciones como los microcréditos y también los recursos que otorgan las fundaciones y las cooperativas, los recursos siguen siendo limitados y las condiciones para acceder a ellos aún siguen siendo restrictivas. Actualmente, el Grameen Bank (la institución de microfinanzas más grande del mundo), creado por el Nobel de Paz Muhammad Yunus en Bangladesh, está interesado en establecer contacto con entidades del gobierno, pues tiene interés en el país debido a su preocupación y búsqueda de soluciones de acceso a la banca formal para personas de bajos recursos, a través de programas como la Banca de las Oportunidades.

El sistema de desembolsos del Grameen Bank tiene las siguientes características (Zúñiga, 2003):

5 El sector informal se define como aquel que, en alguna medida, no cumple con regulaciones legales tales como llevar registros contables, consolidar estados financieros, responder encuestas institucionales, ni con normas fiscales, laborales, urbanísticas, etc. (Ortiz y Uribe, s.f.). 
- Se concentra en los más pobres de los pobres, basados en un sistema claro de selección de los clientes y ha otorgado préstamos principalmente a las mujeres.

- Los prestatarios forman grupos pequeños y homogéneos. Dichas características facilitan la solidaridad grupal, la interactividad y la recolección de la cuota.

- Condiciones especiales para otorgar los prestamos en condiciones favorables para los pobres. Estas incluyen:

1. Pequeños préstamos otorgados sin garantía.

2. Préstamos pagaderos en cuotas semanales a un año.

3. El acceso a nuevos créditos depende del pago del primer préstamo.

4. Actividades individuales que aprovechan la habilidad de la persona para generar ingresos.

5. Supervisión del crédito por parte del grupo y el banco.

6. Énfasis en la disciplina crediticia y responsabilidad colectiva del reembolso.

- El funcionamiento simultáneo de una agenda de desarrollo social que trata las necesidades básicas de la clientela.

- Expansión de la cartera de préstamos para satisfacer las necesidades de desarrollo social y económico de los pobres.

Tabla 6. Rasgos distintivos de la microfinanza

$\begin{array}{lll}\text { Área } & \text { Finanza Tradicional } & \text { Microfinanza } \\ & \text { (1) basada en una garantía } & \text { (1) basada en el carácter } \\ \text { (2) más documentación } & \text { (2) menos documentación }\end{array}$




\begin{tabular}{|c|c|c|}
\hline \multirow[t]{2}{*}{ Área } & Finanza Tradicional & Microfinanza \\
\hline & (3) vencimiento a más largo plazo & (3) vencimiento a más corto plazo \\
\hline \multirow[t]{2}{*}{ Cartera de Préstamos } & 4) más diversificación & (4) menos diversificación \\
\hline & (5) mora más estable & (5) mora más volátil \\
\hline \multirow{3}{*}{$\begin{array}{l}\text { Estructura y Gobierno } \\
\text { Institucional (de ins- } \\
\text { tituciones financieras } \\
\text { reguladas) }\end{array}$} & $\begin{array}{l}\text { (1) Maximización de beneficios para accionistas institu- } \\
\text { cionales e individuales }\end{array}$ & $\begin{array}{l}\text { (1) Fundamentalmente accionistas institucionales sin } \\
\text { fines de lucro }\end{array}$ \\
\hline & $\begin{array}{l}\text { (2) Creación derivada de una institución regulada } \\
\text { existente }\end{array}$ & (2) Creación por conversión de una ONG \\
\hline & $\begin{array}{l}\text { (3) Organización centralizada con sucursales en las } \\
\text { ciudades }\end{array}$ & $\begin{array}{l}\text { (3) Serie descentralizada de pequeñas unidades en áreas } \\
\text { con infraestructura débil }\end{array}$ \\
\hline
\end{tabular}

Fuente: Rock y Otero (1996), Berenbach y Churchill (1997)

\subsection{Evolución reciente de la cartera de microcrédito en Colombia}

Para el año 2009 no dejaron de crecer los desembolsos en microcréditos destinados a pequeños negocios. Estos préstamos no superan los 55 millones de pesos y parecen haberse vuelto el tipo de créditos más resistente a los incrementos de tasas de interés realizados por el Banco de la República. En mayo del 2009, el sistema financiero ya ha hecho desembolsos por 21.5 billones de pesos en créditos nuevos, 11.6 por ciento menos que en el mismo mes del año pasado, según datos suministrados por Asobancaria y el banquero mayor. La caída estuvo jalonada por los préstamos de consumo (tarjetas de crédito, libre inversión, vehículos, etc.) y los comerciales, de los cuales se prestaron 2.8 billones de pesos menos que un año atrás.

La gran excepción fueron los microcréditos, cuyos desembolsos pasaron de 69.675 millones de pesos en mayo del 2008 a 102.674 millones en el mismo mes del 2009 (figura 3). Una explicación para que unos créditos caigan y otros suban puede ser el hecho de que los deudores de consumo y de crédito ordinario son muy sensibles al aumento en las tasas de interés, mientras que los usuarios del microcrédito aceptan una tasa alta, porque su otra alternativa es el especulativo o el paga diario, que cobra intereses "gigantescos".

Es importante reconocer el esfuerzo del gobierno desde el año 2008 por frenar el costo del microcrédito, cuando se congeló la tasa máxima que las entidades pueden cobrar para ese tipo de préstamos en 33.93 por ciento indicando que si se supera ese nivel se incurre en el delito de usura. Ese tope se ha mantenido pese a la molestia de los bancos, quienes insisten que tener ese techo afecta las colocaciones de microcréditos, dado que para ellos cada vez es más caro prestar pequeños montos tras las alzas de tasa de interés realizadas por el Emisor.

Si bien la política contraccionista del Banco de la República ha generado un aumento generalizado de todas las tasas de interés, las de los créditos bancarios suben pero en menores proporciones. El costo promedio de los préstamos del sector financiero pasó de 19.96\% en agosto del 2008 a 21.07\% en 2009. La mayor parte de este incremento corrió por cuenta del aumento en la tasa de interés para consumo, que subió en el mismo durante el mismo periodo de tiempo de $25.51 \%$ a $28.13 \%$. 
Las tasas de interés del microcrédito fueron las que menos aumentaron, justamente porque su tasa de usura está congelada. El costo promedio de un microcrédito pasó de $31 \%$ en agosto del 2008 a 31,55\% en el 2009 (figura 4).

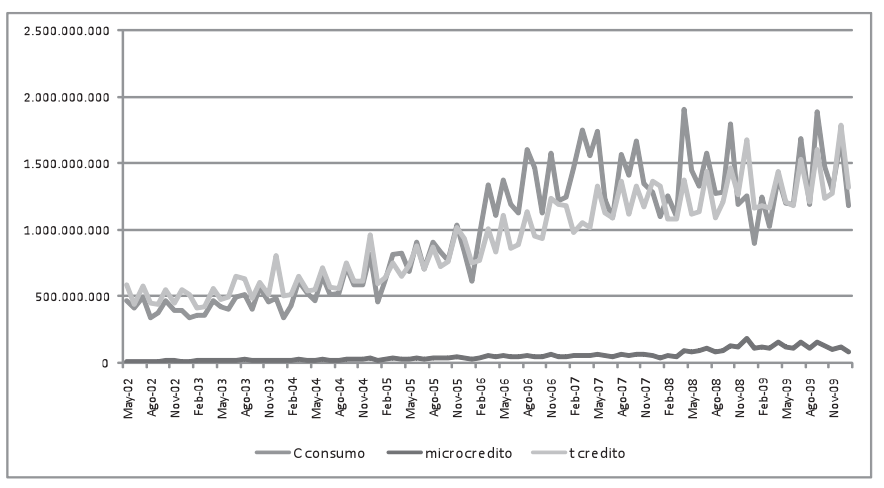

Figura 5. Evolución de los créditos de consumo, tarjetas de crédito y microcrédito en Colombia durante el período 2002-2010 (miles de millones de pesos)

\section{Fuente: recuperado el 13 de abril de 2010 desde} $<$ http:/www.asobancaria.com>

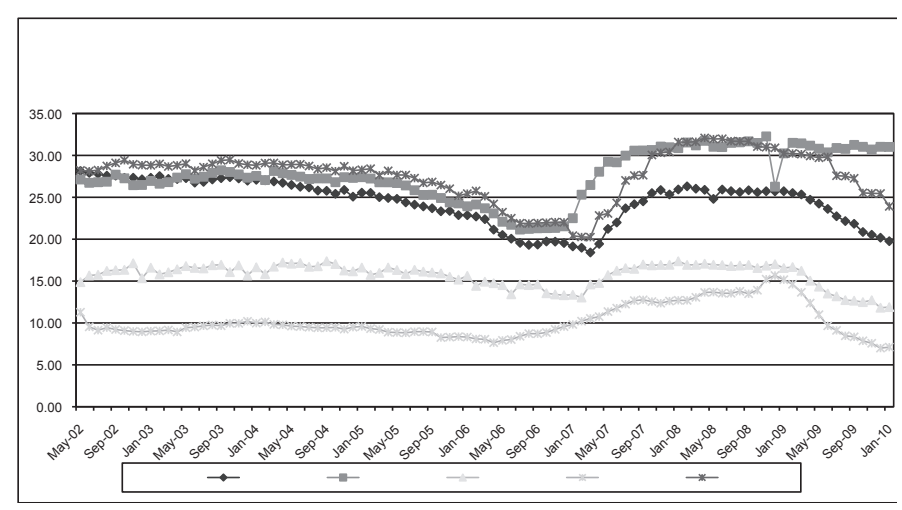

Figura 6. Evolución de tasas de interés de créditos durante el período 2002-2010

Fuente: recuperado el 14 de marzo de 2010 desde $<$ http:/www.asobancaria.com>

\section{Conclusiones}

Como actividad de financiación, los créditos pueden ser un elemento importante para el desarrollo y el bienestar de la sociedad, cuando estos recursos llegan a un gran número de empresas o personas. Sin embargo, en una sociedad como la nuestra donde los mercados son imperfectos e incompletos y se presenta mucha incertidumbre, el acceso a este tipo de recursos es cada vez más limitado, bien sea por los altos costos de intermediación, la escasez de recursos de los solicitantes de créditos, la falta de garantías, el aumento en las tasas de interés, la disposición a pagar, la pérdida de confianza de las entidades financieras, las fluctuaciones del mercado y el comportamiento socioeconómico en general. Estas razones han motivado a que muchas entidades financieras sean restrictivas al momento de otorgar los créditos, principalmente para los pequeños productores y empresarios informales y para aquellos grupos sociales más vulnerables de la población, quienes al no acceder a este tipo de recursos limitan aún más su capacidad productiva y mejora en la calidad de vida.

Durante los últimos años han surgido nuevas propuestas que permiten en cierta medida aliviar las anteriores deficiencias y contrarrestar las restrictivas condiciones impuestas por los canales de crédito convencional y los créditos informales. Es por ello que han surgido canales alternativos de financiación como los microcréditos, los créditos de fomento y otras modalidades de créditos blandos otorgadas a través de fundaciones y cooperativas, donde se acepta que estos préstamos pueden tener incidencia en la calidad de vida, al liberar recursos que permiten crear empresas, mejorar la calidad de la alimentación de las familias pobres o permitir el acceso de los niños a la salud y la educación. Esta financiación debe tener un costo y es que los pobres deben ser beneficiarios de oportunidades y no de subsidios. Sin embargo, no todas las características del microcrédito generan acuerdos, 
pues hay puntos de discusión como las tasas de interés, algún subsidio a los costos financieros de estos créditos, orientar los microcréditos sólo hacia los más pobres y hacer obligatoria la capacitación de los microempresarios para hacer más adecuado el manejo de estos recursos.

A nivel teórico, muchos autores han estudiado los motivos por los cuales los créditos son cada vez más restrictivos en un escenario de competencia imperfecta, al explicar algunas de sus características. No obstante, convergen en un mismo punto: persisten problemas de selección adversa, riesgo moral, ejecución de contratos y una mayor presencia de créditos informales altamente riesgosos. Por otra parte, algunas teorías explican la restricción de los créditos a partir de las elevadas tasas de interés y se basan en el concepto del riesgo del prestamista, mientras otras consideran que el crédito es una excusa para transferir una garantía del prestatario al prestamista.

Lo anterior obedece a que los mercados de crédito son imperfectos y se presentan problemas como la incapacidad de devolver el préstamo y el problema de la negativa a devolverlo. Estos problemas son a su vez el resultado de la información asimétrica cuando la entidad financiera no conoce realmente el destino de los recursos. Asimismo, la posible ausencia de un flujo de información sobre los prestatarios.

En Colombia uno de los canales de financiación más utilizados por hogares pertenecientes a los estratos 1, 2 y 3 son los créditos informales, los cuales son de fácil acceso y otorgados a corto plazo, pero representan altos costos para los usuarios, quienes deben pagar elevados intereses y asumir grandes riesgos cuando incumplen con estas obligaciones. La modalidad de crédito formal es asumida por hogares, de estrato 3 principalmente, y sus fuentes provienen de los bancos, fondos de empleados y las cooperativas. Sus principales usuarios son aquellas personas que obtienen ingresos estables y están vinculados a algu- na actividad económica formal. Igual sucede con aquellas microempresas, las cuales a medida que poseen un mayor patrimonio recurren al sistema financiero y a los proveedores. Pero lo crítico de esto es la restricción que ocasionan los créditos formales para aquellas personas que carecen de ingresos y acceso a entidades de financiación tradicional.

Aunque en Colombia han surgido otras formas de financiación alternativa como los microcréditos, estos llegan a un número limitado de usuarios, los cuales se ofrecen con altas tasas de interés, y restringen aún más el acceso a estos recursos para personas carentes de ingresos. Algunas entidades como ONG o fundaciones también participan en el mercado de los microcréditos apoyando especialmente a grupos solidarios a través del programa de Banca de Oportunidades, pero estos recursos son insuficientes para lograr una mayor cobertura a numerosos sectores pobres de la población, y además son créditos de baja cuantía, que apenas cubren necesidades básicas, y no permiten generar proyectos de inversión. Por tanto, a pesar de existir nuevos canales crediticios, este mercado en Colombia sigue siendo imperfecto y no alcanza a generar un nivel de desarrollo, especialmente para aquellos microempresarios informales y personas de bajos recursos.

\section{Agradecimientos}

El desarrollo de este artículo fue posible gracias al apoyo y al interés que ha prestado la Maestría de Ciencias Económicas de la Universidad Santo Tomás a través del Grupo de investigación GRIES, dentro de cuyos planes de investigación se encuentra el desarrollo del tema de la financiación y su relación con el entorno social. La idea es investigar posteriormente las limitantes que han tenido el acceso a los créditos en los sectores más vulnerables de la población, y la posibilidad para que estos grupos accedan a las microfinanzas como alternativa de financiación. 


\section{Referencias}

Bernanke, B. (1993). Gredit in the Macroeconomic. Federal Reserve Bank of the New York, Quarterly Review, 50-70.

Bernanke, B. \& Gertler, M. (1989). Agency Costs, Net Worth, and Business Fluctuations, American Economic Review, 79, 14-33.

Blanchard, O. J. \& Fisher, S. (1999). Lectures on Macroeconomics. The MIT Press.

Browne, L. \& Rosengren, E. (1992). Real Estate and the Credit Crunch. New England Economic Review.

Cahuc, P. (1996). La Nueva Microeconomía. Bogotá: AlfaOmega - Universidad Nacional de Colombia - Facultad de Ciencias Económicas.

Clair, R. \& Tucker, P. (1993). Six Causes of the Credit Crunch, Economic Review: Third Quarter. Dallas: Federal Reserve Bank of Dallas.

Corredor, A. y Pérez, R. (2009). El mercado de crédito comercialy las restricciones de endeudamiento en Colombia. Reporte de Estabilidad Financiera. Bogotá: Banco de la República.

Debraj, R. (2002). Economía del desarrollo. Barcelona: Antoni Bosch Editor.

Econométrica S.A. (2007). Encuesta de Mercado de Crédito Informal en Colombia. Programa MIDAS.

Guillen, R. (1997, noviembre). Globalización financiera y riesgo sistémico. Revista de Comercio Exterior, 870-880.
Hodgman, D. (1960). The Quarterly fournal of Economics, 2, (74), 258-278.

Marín, J. y Rubio, G. (2001). Economía Financiera. Barcelona: Antoni Bosch Editor S.A.

Parikshit, G. Dilip, M. \& Debraj, R. (1999). Credit Rationing in Developing Countries. An Overview of the Theory. A Reader in Development Economics. London: Blackwell.

Pino, E. (2002). Financiamiento para la pequeña empresa. Una aproximación desde la sociedad civil. Comercio Exterior, 5, (52).

Riley, J. (1987, March). Credit Rationing A Further Remark. The American Economic Review.

Rock, R. \& Otero, M. (1996). From Margin To Mainstream: The Regulation and Supervision of Microfinance (Accion Monograph Series, No. 11).

Schiantarelli, F. (1996). Financial Constraints and Investment: Methodological Issues and International Evidence, Oxford Review or Economic Policy, 12, 70-89.

Stiglitz, J. \& Weiss. (1981). Credit Rationing in Markets with Imperfect Information. American Economic Review, 393-410.

Uribe, J. (2009, septiembre). Nota Editorial. Revista Banco de la República.

Urrutia, M. (2001, diciembre). El crédito del sector financiero: su evolución en el último lustro e interpretaciones. Revista del Banco de la República, 890. 
Las imperfecciones del mercado de créditos, la restricción crediticia y los créditos alternativos Gustavo Adolfo Díaz Valencia

Williamson, S. (1987). Costly Monitoring, Loan Contracts, and Equilibrium Credit Rationing. Quarterly Journal of Economics.

Wolfson, M. (1996). A Post Keynesian Theory of Credit Rationing. Fournal of Post Keynesian Economics, 3, (18).
Zúñiga, S. (2003). Caso de Estudio Microcrédito como herramienta de Desarrollo Regional. Microfinance at the University Commision at the European Communities under the ALFA Program. Santa Cruz, Bolivia. 